\title{
Cooperação, Liderança e Impasse entre 0 Legislativo e o Executivo na Produção Legislativa do Congresso Nacional do Brasil
}

\section{Fábio de Barros Correia Gomes}

Professor do mestrado profissional em ciência política do Centro de Formação, Treinamento e Aperfeiçoamento da Câmara dos Deputados (CEFOR) e consultor legislativo da Câmara dos Deputados. E-mail: fabio.gomes@camara.gov.br.

\section{INTRODUÇÃO}

$\mathrm{O}$ estudo da interação entre o Legislativo e o Executivo federais do Brasil na produção de leis tem apresentado considerável desenvolvimento, graças ao acúmulo de informações sobre essas instituições complexas. Durante a década de 1990, a discussão sobre esse tema produziu dois polos com diagnósticos diametralmente opostos. Um deles apontava para a paralisia decisória, e o outro, para a governabilidade com preponderância do Executivo. O primeiro indicava que a combinação do presidencialismo com um sistema eleitoral altamente proporcional (na seleção de deputados) e geograficamente desbalanceado desestruturaria o sistema partidário e geraria um excesso de pontos de vetos, dificultando a definição de políticas públicas de interesse amplo e, ao mesmo tempo, facilitando os ganhos de grupos de interesse, conduzindo ao caos institucional. Nessa abordagem distributivista, o presidente não conseguiria aprovar sua agenda diante de um Congresso fragmentado e particularista (Ames, 2001; Mainwaring, 1993). Contudo, o reconhecimento internacional obtido pelo Brasil na implantação de políticas econômicas e sociais consistentes, estáveis e de interesse amplo, contrariou tais prognósticos ${ }^{1}$, demandando uma maior compreensão sobre o processo de elaboração de políticas públicas no país e uma reavaliação dos pressupostos sobre a organização institucional brasileira (Kingstone e Power, 2008).

DADOS - Revista de Ciências Sociais, Rio de Janeiro, vol. 55, n²4 2012, pp. 911 a 950. 
Alguns autores ainda recorrem à formulação de um paradoxo: como instituições inadequadas seriam capazes de gerar políticas relevantes e equitativas? Uma vertente revisionista mantém intacto o pressuposto distributivista, substituindo a paralisia decisória pela possibilidade de sucesso por meio da informalidade das relações institucionais, pois a fluidez nas relações facilitaria a adoção de políticas consideradas necessárias pelas elites (Armijo, Faucher e Dembinska, 2006).

A percepção da paralisia decisória foi desafiada, ainda na década de 1990, por dados empíricos sobre a produção legislativa, que reconheceram uma importante atuação do Executivo, com uma taxa de sucesso de aproximadamente $90 \%$ e, além disso, foi autor de $86 \%$ da produção legal (Figueiredo e Limongi, 1999; 2004). Os potenciais excessos de veto ocasionados pelo sistema eleitoral não conseguiriam reproduzir completamente a conexão eleitoral na esfera legislativa, devido à limitação da obtenção de benefícios particularizados nesta. Isso porque o Congresso disporia de regras que centralizariam o processo decisório, favorecendo a atuação dos líderes partidários nas interações com o presidente.

A base da argumentação dos que reconhecem a governabilidade propiciada pelo arranjo institucional depende de dispositivos explicitados na Constituição de 1988, o que se constitui importante diferencial em relação ao outro polo do debate. O presidencialismo de coalizão (em que a capacidade para implementar uma agenda de governo depende de decisões estratégicas do presidente para constituir uma coalizão de governo) possibilitaria a governabilidade e a predominância do Executivo resultaria de seu maior acesso a recursos legislativos disponíveis ao presidente (Abranches, 1988; Pereira e Mueller, 2000; Amorim Neto, Cox e McCubbins, 2003; Santos, 2003). Consequentemente, a agenda e a legislação resultante seriam predominantemente de abrangência nacional, pela tendência de o Executivo responder a demandas nacionais e de os parlamentares sinalizarem suas preferências ao eleitorado por meio de apoio, ou não, à coalizão de governo (Amorim Neto e Santos, 2003).

Inicialmente, foi proposto que a predominância do Executivo seria acompanhada de uma separação das agendas dos poderes: o Executivo lidaria com temas econômicos e administrativos, enquanto o Legislativo, com os sociais (Figueiredo e Limongi, 1999; Santos, 2003; Amorim Neto e Santos, 2003), contudo, estudo sobre os temas das 
emendas orçamentárias apresentadas por parlamentares entre 2001 e 2003 mostrou que as modificações efetivadas pelo Legislativo na lei orçamentária complementavam as prioridades indicadas pelo Executivo, de modo que haveria uma "fusão da agenda" substantiva do Executivo e de parte do Legislativo, que não apenas anteciparia, mas incorporaria a reação do Legislativo (Figueiredo e Limongi, 2009).

Apesar de, no período recente, as evidências favorecerem as argumentações do segundo polo, alguns dados adicionam questionamentos sobre a interação entre os poderes na produção de leis. Por exemplo, a partir de 1994 o Legislativo tem aumentado sua participação como autor de leis ordinárias provenientes de projetos de lei ordinária, superand o o quantitativo produzido pelo Executivo (Figueiredo e Limongi, 1999), e essa tendência tem sido mantida em períodos mais recentes (Carvalho e Gomes, 2008; Carneiro, 2009) ${ }^{2}$. As intensas atividades de modificação de projetos e de atuação das comissões permanentes sugerem que os interesses dos parlamentares podem ser mais amplos do que se atribui atualmente (Amaral, 2011; Carneiro, 2009; Cruz, 2009) ${ }^{3}$. Santos (1997), por meio de estudos de casos sobre a produção de legislação de elevada saliência na área fiscal, tributária e de definição do salário mínimo, observou conflito e cooperação, contrapondo-se a uma cooperação orientada pelo Executivo, depreendida a partir de análises agregadas.

Uma melhor compreensão do modo como se dá a interação entre os poderes para a produção legislativa importa para os que se interessam por questões como a governabilidade e a representatividade do sistema político. Este artigo busca aprofundar a análise do papel dos poderes na produção legislativa nacional, com ênfase na análise de dados empíricos que qualifiquem a predominância do Executivo nessa produção (a tese com maior evidência empírica e plausibilidade, logo, selecionada como ponto de partida) e na busca dos mecanismos causais relacionados.

\section{METODOLOGIA}

Inicialmente, foram identificadas questões metodológicas que teriam produzido os diagnósticos tão diferenciados já mencionados. Uma delas seria uma excessiva ênfase em modelos de organização legislativa simplificados para representar instituições tão complexas. As perspectivas distributiva, partidária e informacional (originalmente destina- 
das a esclarecer o funcionamento do fortalecido sistema de comissões do Congresso dos Estados Unidos da América [EUA]) em geral têm sido consideradas como modelos exclusivos, mas como abordam diferentes dimensões da organização legislativa (respectivamente: tipos de políticas produzidas, organização do processo decisório e recursos para decisão), seria possível uma superposição desses fatores ao longo do tempo, à medida que as instituições se desenvolvam.

No caso da tese da paralisia decisória, a adoção de pressuposto excessivamente distributivista e a pouca consideração da potencialidade das novas regras constitucionais, em um contexto de falha governamental e de crise da década de 1990, pode ter prevenido a consideração de hipóteses alternativas. A reação a esse tipo de diagnóstico, segundo a tese da governabilidade com predominância do Executivo, fundamentou-se, em grande parte, na perspectiva partidária, alcançando grande poder explicativo.

Entretanto, alguns aspectos metodológicos podem estar dificultando a percepção dos efetivos papéis dos poderes e da agenda discutida no Congresso. Merecem atenção as fragmentações nas análises relacionadas à seleção: a) dos atores (poucos estudos abordam os senadores); b) dos locais onde as decisões são tomadas (o plenário da Câmara tem sido privilegiado); c) dos tipos de proposições e de vias legislativas utilizadas (propostas de emenda à Constituição e projetos de lei complementar são pouco estudados); e, principalmente, d) da agenda efetivamente discutida no Congresso (geralmente tem sido desprezada a agenda dos parlamentares que não foi convertida em lei).

Também foram identificadas: a) carência de abordagens qualitativas que valorizem o conteúdo e relevância das matérias e os conflitos por elas gerados; riscos na agregação indiscriminada de proposições, em que análises podem ser influenciadas pelos atributos das mais frequentes, perdendo variações daquelas menos frequentes, mas, talvez, de maior relevância para as políticas públicas; b) potenciais distorções causadas pela valorização da autoria como determinante único de liderança; e c) desconsideração da regra constitucional que reserva a iniciativa de matérias administrativas e orçamentárias ao Executivo.

Vários autores já defenderam a necessidade de considerar mais de uma perspectiva teórica, além da distributivista, para a compreensão do caso brasileiro (Carvalho, 2003; Amorim Neto e Santos, 2003; Cintra, 2007; Almeida e Santos, 2009). Santos (1997) observou que opções me- 
todológicas podem interferir nas conclusões de estudos sobre a relação entre o Executivo e o Legislativo e a capacidade governativa no Brasil, destacando a necessidade de "ponte metodológica" para a análise de resultados conflitantes.

Considerando esse contexto, foi elaborado um modelo para o sistema de produção legislativa no Brasil que abordasse os principais problemas detectados. Este considerou a vasta produção nacional, mas também sofreu influência da concepção teórica de institucionalismo histórico, como percebido nas pesquisas de LeLoup e Shull (2002) e de Jones (2005) sobre o relacionamento entre o presidente e o Congresso dos EUA. LeLoup e Shull (2002) avaliaram a evolução histórica dos poderes constitucionais dos EUA, identificando os limites e potencialidades dos atores na produção de leis. Utilizaram tipologia baseada no nível de conflito gerado pelo conteúdo da política e no tipo de liderança do presidente e do Congresso, identificando interações caracterizadas por liderança de um dos atores, cooperação ou impasse. Jones (2005) reconheceu a necessidade de identificação dos recursos disponíveis, das vantagens e das posições estratégicas dos atores, para identificar os tipos de interação entre o presidente e o Congresso. Por meio da análise da história legislativa de casos significativos, identificou níveis de competitividade entre os partidos e destacou situações de liderança do presidente, do Congresso ou balanceadas.

Na perspectiva desses autores, a ênfase não se situa na identificação de instituição predominante, mas se o sistema é capaz de solucionar os problemas colocados na agenda política. Embora essas instituições possuam regras diferentes das brasileiras, apresentam similaridades que podem tornar as reflexões desses autores úteis para o caso do Brasil. Entre essas características destacam-se a existência de poderes institucionalmente separados, com membros democraticamente eleitos, que compartilham poder e que precisam interagir para que políticas públicas sejam elaboradas.

O modelo concebido para o estudo buscou integrar a percepção sistêmica no nível de análise das macroinstituições (os poderes) com aquela das estratégias no nível da microanálise política (atores individuais), na tentativa de superar a fragmentação produzida pela análise isolada dos elementos e pela adoção de pressupostos institucionais que enfatizam apenas as demandas por políticas particularizadas, ou a media- 
ção dos partidos, ou a necessidade de recursos informacionais. Um mapa conceitual é apresentado na Figura 1.

Seus principais elementos são: as regras estruturantes, os atores, as instâncias de decisão, os recursos e as políticas públicas (o resultado). As demandas por políticas que conseguem compor a agenda legislativa são os insumos do sistema. A estrutura é oferecida pela norma legal de maior status, a Constituição Federal, historicamente determinada e continuamente modificada, em função de alterações críticas de poder ${ }^{4}$. Por um lado, essa estrutura favorece a governabilidade com accountability, para evitar a paralisia decisória que ocorreu no período imediatamente anterior ao governo militar iniciado em 1964. Tal governabilidade seria garantida pelo nível de flexibilidade que o Executivo teria para adotar legislação oportuna para o enfrentamento de problemas econômicos e sociais (segundo uma conexão eleitoral de amplitude nacional), contando com a cooperação do Legislativo, por meio de uma agenda negociada. Essa flexibilidade, entretanto, estaria limitada por arranjos institucionais, os quais mantêm o poder do Congresso de se manifestar sobre todas as propostas de leis e que dificultam modificações nas normas de níveis hierárquicos superiores. A busca de uma maior accountability do presidente é exemplificada pela exigência de autorização legislativa em vários tipos de movimentações orçamentárias específicas e pela previsão de crime de responsabilidade em várias situações de natureza política, mas também em outras de efeito pragmático, como no caso de execução de investimento sem prévia inclusão no plano plurianual, ou sem lei que autorize a inclusão.

Por outro lado, essa estrutura também favorece o desenvolvimento de políticas de interesse social. A "constitucionalização" de políticas que poderiam ter sido tratadas em leis buscou solidificar ganhos sociais em um nível em que o campo de atuação do Executivo estaria mais limitado, em função das exigências para modificação do texto constitucional, resultando em path dependencies a serem seguidas pelo Executivo e na conexão normativa entre o texto constitucional e legislações futuras. Essa estrutura recebe o suporte de normas de hierarquia inferior, como os regimentos das casas legislativas, que terminam por oferecer aos atores vias estratégicas distintas para atingirem seus objetivos ${ }^{5}$. As regras conformam três vias legislativas hierarquizadas: a constitucional, a complementar e a ordinária. 
Cooperação, Liderança e Impasse entre o Legislativo e o Executivo na Produção...

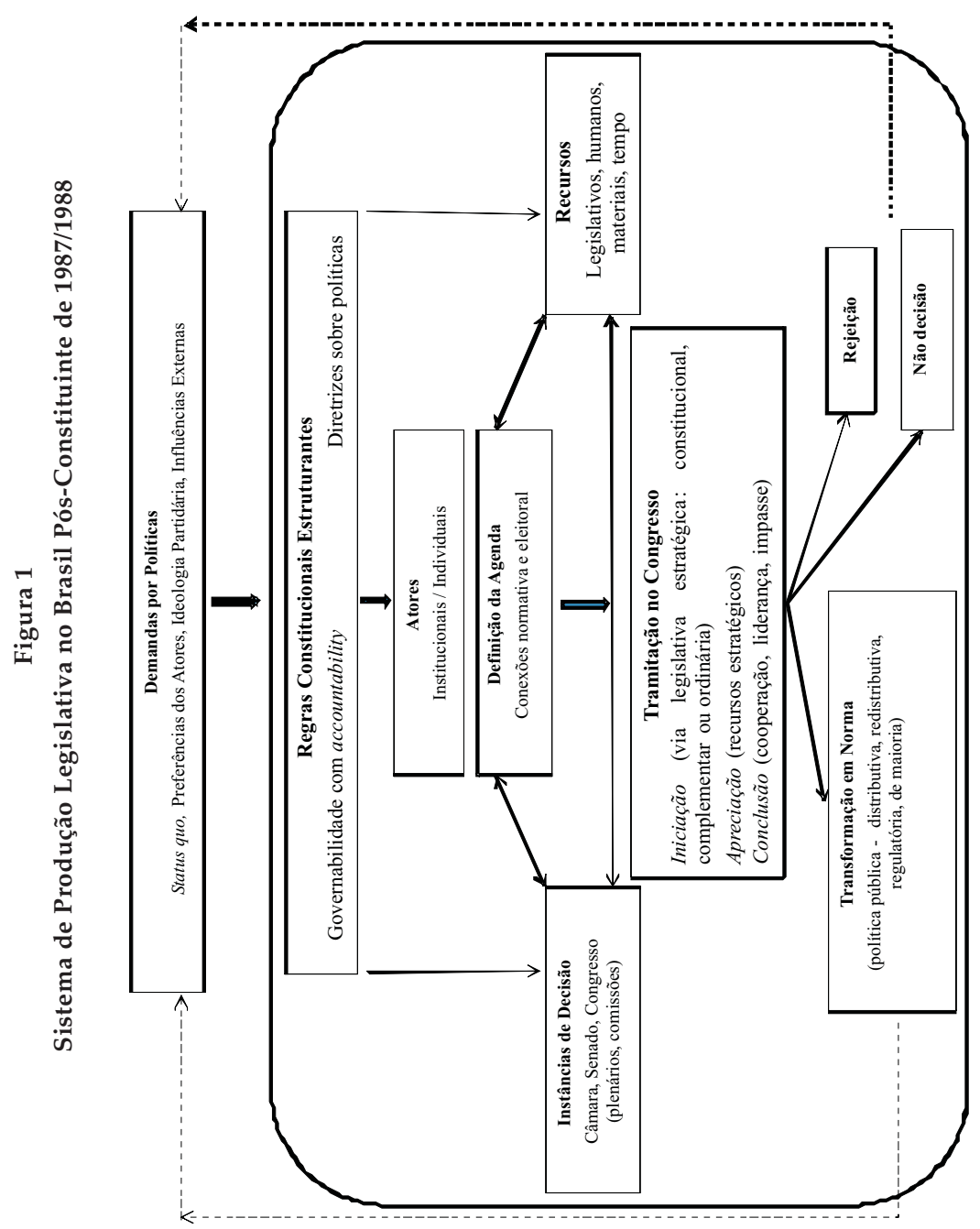

$\dot{0}$
0
0
0
0
0
0
0
0
0
0
0
$\frac{0}{0}$
0
0
0
0
0
0
0
1 
A via constitucional utiliza apenas um tipo de proposição legislativa, a proposta de emenda à constituição (PEC), a qual, para ser aprovada, requer uma super maioria de três quintos dos membros do Congresso em duas votações nos plenários de cada Casa. Embora tanto o Legislativo quanto o Executivo possam iniciar uma PEC, esta não pode ser objeto de urgência ou de veto presidencial.

A via complementar também dispõe de apenas um tipo de proposição, o projeto de lei complementar (PLP), cujos objetos estão especificamente mencionados na Constituição, pois que seu principal papel é o de complementá-la em alguns relevantes tópicos. Para ser aprovado, um PLP deve passar pelo plenário de cada Casa sob a regra da maioria absoluta. Não é permitida a a provação conclusiva de projetos pelas comissões, ou seja, sempre serão apreciados pelo plenário (pelo menos na Câmara). O PLP está sujeito ao regime de urgência e ao veto presidencial.

A via ordinária produz leis ordinárias a partir de três tipos de proposições: o projeto de lei ordinária (PL), a medida provisória (MPV) e o projeto de lei do Congresso Nacional (PLN), sendo os dois últimos usados exclusivamente pelo Executivo. O PL possui o maior número de autores potenciais, pois pode ser iniciado por membros do Legislativo, Executivo, Judiciário e, até, por cidadãos (em condições específicas). O PL precisa ser aprovado em cada Casa, segundo uma regra de maioria simples. Contudo, pode ser apreciado conclusivamente pelas comissões, ou seja, tornar-se lei sem a aprovação do plenário. O PLN relaciona-se ao orçamento federal e é apreciado em sessões conjuntas do Congresso e deliberado em apenas um turno de votação, sob a regra de maioria simples. A MPV tem força imediata de lei e validade de até 120 dias para que o Congresso a rejeite ou a converta em lei ordinária (se houver modificação de conteúdo, será necessária a aprovação de um projeto de lei de conversão). Caso o Congresso não delibere nos prazos requeridos, a pauta do plenário da Casa em que tramita é sobrestada até que uma decisão seja tomada. O regime de urgência e o veto presidencial são permitidos nessa via.

Após os autores selecionarem a via legislativa mais adequada, segundo seus objetivos de política e poder político, as proposições são consideradas em múltiplas instâncias de decisão (comissões permanentes ${ }^{6}$, comissões temporárias e plenários de cada Casa, além de sessões conjuntas do Congresso para deliberar, por exemplo, sobre o orçamento e 
vetos presidenciais). Esses locais são predeterminados de acordo com o conteúdo e relevância. Neles, os atores interagem, usando os recursos disponíveis. Alguns destes são de natureza legislativa, como o requerimento de urgência e a competência de os coordenadores dos locais de decisão inserir as matérias nas pautas de deliberação; outros são não legislativos, como o tempo, recursos humanos, materiais e informacionais.

Geralmente, há uma sequência linear na tramitação: após a aprovação pelas comissões, os projetos de lei são votados pelo plenário e, então, são considerados pela outra Casa. Se o projeto for emendado precisa voltar à Casa de origem para avaliação específica das emendas. Uma vez aprovado em cada Casa, o projeto segue para a sanção do presidente da República, o qual pode sancioná-lo ou vetá-lo (inteiramente ou em partes). O veto pode ser derrubado pela metade dos membros de cada Casa. Enfim, os outputs mais destacados do sistema são as leis com impacto em políticas públicas ${ }^{7}$. Outros resultados possíveis são a rejeição e a não decisão sobre a política.

Esse marco institucional possibilita a ocorrência de tipos de interação entre os poderes, como: liderança de um dos atores, cooperação e impasse. Estes tipos baseiam-se no padrão de liderança (para iniciar, modificar ou aprovar projetos) e no nível de conflito entre os mesmos (expresso nos esforços para modificar ou bloquear os projetos). A cooperação é esperada em temas administrativos de rotina, conteúdos com baixo nível de conflito distributivo e em casos de barganha política. A via ordinária seria a mais provavelmente envolvida. O uso de recursos seria moderado e a tramitação, consensual, com tempo de deliberação intermediário (em relação a outros tipos).

A liderança da coalizão de governo é esperada em conteúdos com moderado a elevado impacto distributivo e naqueles de interesse direto do presidente (afetando a governabilidade, accountability e o orçamento federal) e da coalizão. A liderança do Legislativo seria esperada em conteúdos com baixo conflito distributivo, naqueles com amplo suporte da sociedade, naqueles abordando competências do Legislativo, nos que produzam grande controvérsia social (demasiadamente arriscados para que o presidente tome partido) e nos projetos simbólicos. O impasse seria esperado nos casos em que a oposição tentasse aprovar legislação que contrariasse a coalizão em maioria (em quaisquer das vias) e quando a coalizão tentasse usar a via constitucional sem o apoio 
de uma super maioria, geralmente em temas de elevado conflito distributivo.

Definido o marco institucional do estudo, as análises foram orientadas por questionamentos descritivos, buscando verificar: diferenças no padrão de produção que justifiquem o estudo de cada via legislativa (a partir da análise da utilização das vias a partir do século XX); se tem ocorrido segmentação na agenda legislativa dos poderes, segundo conteúdo, e se o Executivo tem predominado na utilização de recursos legislativos e na produção legislativa, considerando o conteúdo das proposições, particularmente seu nível de relevância.

Como questões analíticas, foram avaliadas as relações entre o nível de exigência das regras e as taxas de sucesso e de dominância dos atores; bem como entre conteúdos que afetam a governabilidade e os tipos de interação entre os poderes observáveis no sistema. Para abordar a maioria das questões, foi analisada a tramitação de todas as 21.447 proposições com capacidade para alterar lei ou a Constituição, apresentadas na Câmara dos Deputados, no Senado Federal e no Congresso Nacional em duas legislaturas (entre 1999 e 2006). Os bancos de dados foram construídos a partir de informações coletadas nos sítios da internet da Câmara dos Deputados, do Senado Federal, da Presidência da República e do mecanismo de busca do Lexml, além de planilhas eletrônicas sobre situação de tramitação fornecidas pelos setores de informática das duas primeiras instituições. O banco de dados do Centro Brasileiro de Análise e Planejamento (Cebrap) foi utilizado para verificação da consistência de informações de projetos do Executivo e dos convertidos em lei. Foram coletadas informações sobre autoria, área de conteúdo - conforme denominações utilizadas por Figueiredo e Limongi (1999) -, utilização de recursos legislativos, situação (verificada em março de 2009) e tempo de tramitação.

A análise qualitativa foi aprofundada pela aplicação da primeira versão da classificação de proposições legislativas do Grupo de Pesquisa e Extensão sobre Política de Saúde da Câmara dos Deputados (GPE Saúde) (Gomes, Carvalho e Reis, 2009) a um subconjunto com 5.319 proposições relacionadas à saúde 8 .

\section{RESULTADOS}

Os resultados são apresentados segundo as questões descritivas e analíticas mencionadas. 
Cooperação, Liderança e Impasse entre o Legislativo e o Executivo na Produção...

\section{Padrões de Produção das Vias Legislativas}

Até a década de 1960, a via constitucional foi pouco utilizada (Gráfico 1), visto que muitas das demandas causadas por alterações críticas no balanço de poder foram satisfeitas pela troca da própria Constituição. Durante o período de governo militar, iniciado em 1964, entretanto, aumentaram consideravelmente as alterações de partes da Constituição, pois se, em um período anterior de 38 anos (1926 a 1963), nove emendas haviam sido promulgadas, nos seguintes 22 anos (1964 a 1985) foram produzidas 43 emendas. No atual período constitucional, a tendência foi até ampliada e nos últimos 19 anos foram produzidas 66 emendas, com uma aceleração ocorrendo a partir de 1995 (Gráfico 1), logo, após a revisão constitucional de 1993.

Na via complementar, o quantitativo de leis já produzidas $(169$, desde 1962 - Gráfico 2) é um pouco superior ao de emendas constitucionais (118, desde 1926 - Gráfico 1), contudo, jamais foram elaboradas mais

Gráfico 1

Frequência de Emendas Constitucionais Promulgadas de 1926 a 2010

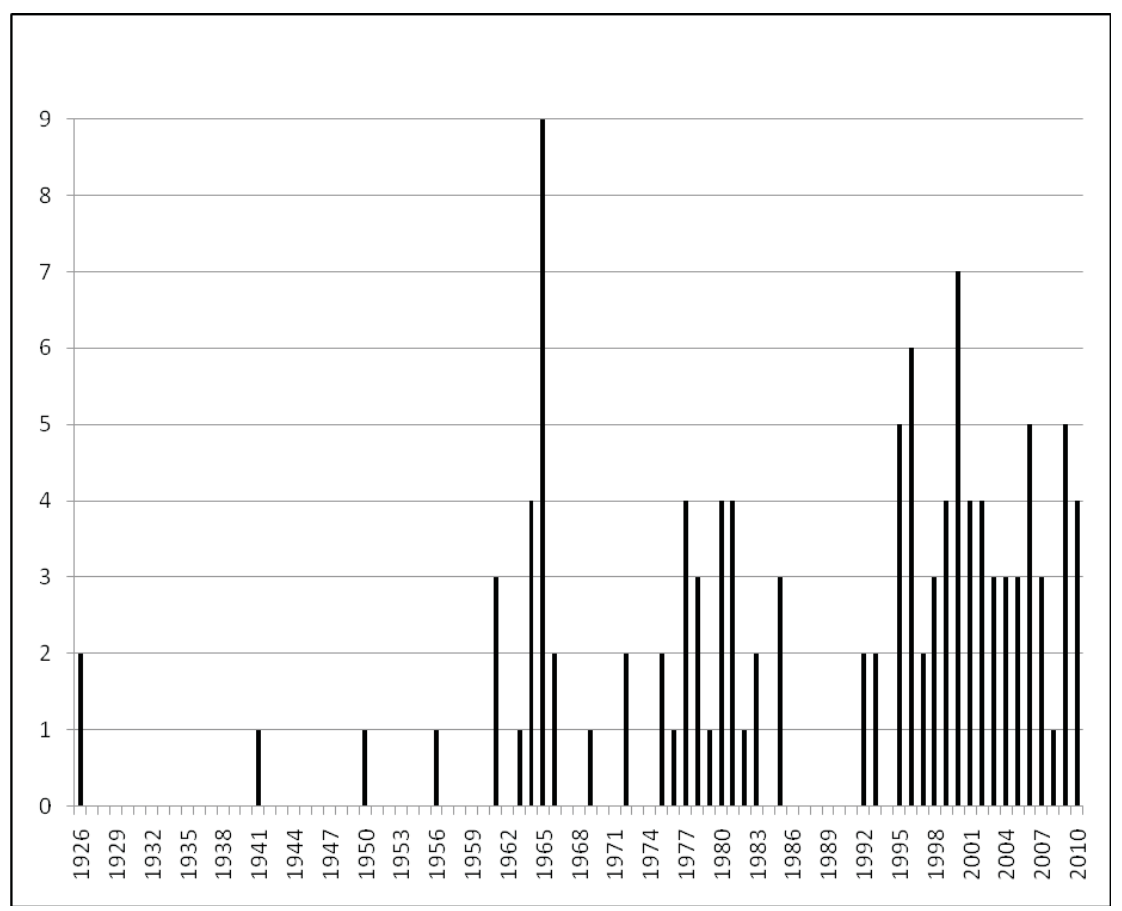

Fonte: Mecanismo de busca do Lexml (http://www.lexml.gov.br). 


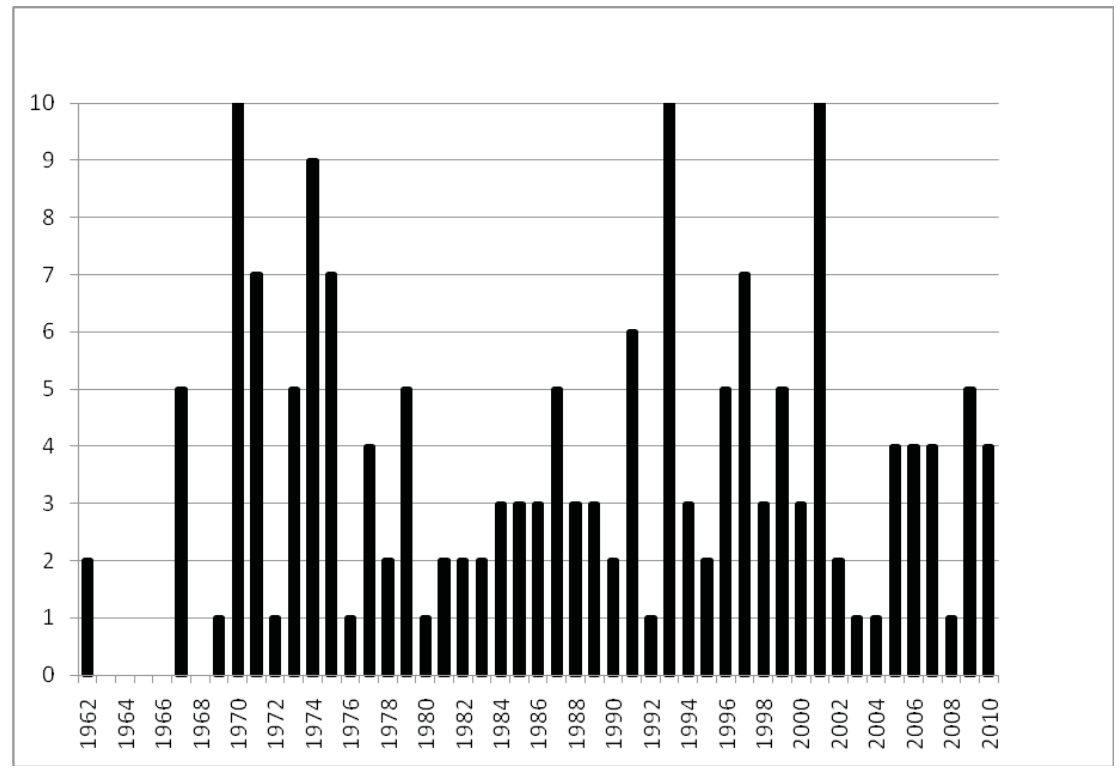

Fonte: Mecanismo de busca do Lexml (http:/ / www.lexml.gov.br).

que 10 leis complementares em um ano, de modo que é uma via com produção quantitativa bem inferior à ordinária. Antes do governo militar de 1964, foram produzidas apenas duas, mas entre 1964 e 1985, 70; e desde 1988, 88 leis complementares (Gráfico 2).

A via ordinária tem sido a de maior frequência de utilização, principalmente nos períodos democráticos da República. Foi mais intensa a produção de leis ordinárias entre 1947 e 1963 (média anual de 260 leis), enquanto entre 1935 e 1937 a média foi de 186 leis anuais; entre 1964 e 1987, de 139; e entre 1988 e 2010, de 204 leis anuais (Gráfico 3).

Contudo, já foi destacado que as leis ordinárias produzidas atualmente não derivam apenas de PL, mas também de PLN e MPV. O uso dos PLN iniciou-se com o governo militar de 1964 (Gráfico 4) em temas de alta relevância institucional e orçamentária, particularmente a partir de 1972 (atualmente apenas se observa uso na área orçamentária). A média de apresentação de PLN foi de 55 por ano, entre 1972 e 1987, e aumentou para 92 projetos anuais de 1988 até o presente. Esse tipo de proposição não apresenta o padrão de elevação de frequência nos primeiros anos das legislaturas. 
Cooperação, Liderança e Impasse entre o Legislativo e o Executivo na Produção...

Gráfico 3

Frequência de Leis Ordinárias Produzidas no Brasil entre 1899 e 2010

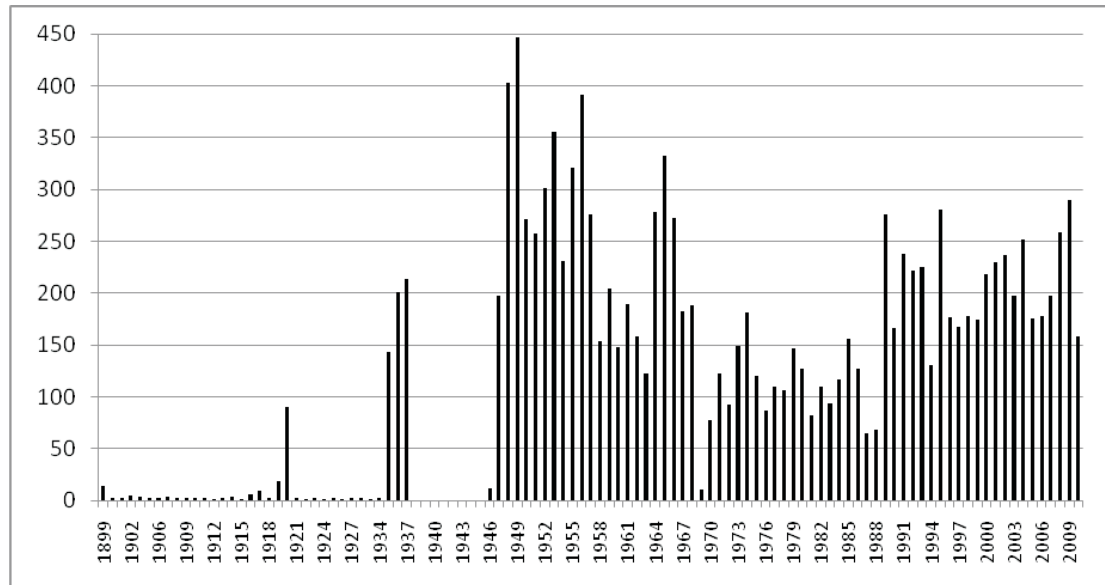

Fonte: Mecanismo de busca avançada sobre legislação do sítio da internet da Câmara dos Deputados (http://www.camara.gov.br).

Gráfico 4

Frequência de Projetos de Lei do Congresso Nacional com Ingresso entre 1964 e 2010

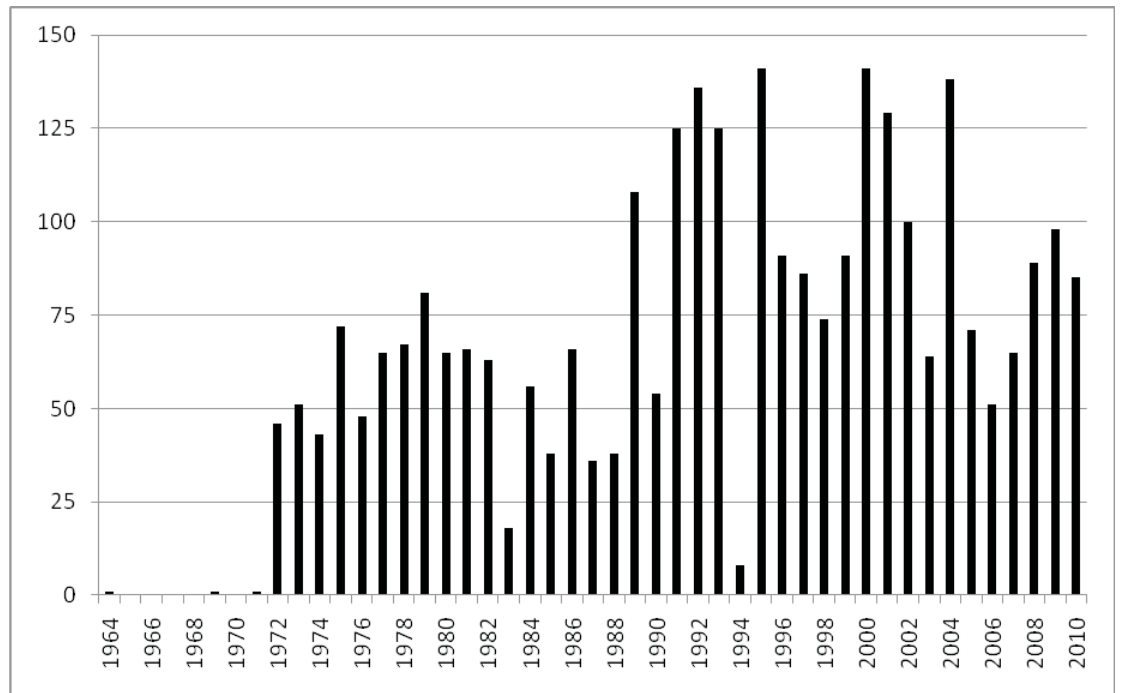

Fonte: Mecanismo de busca avançada do Sicon do sítio da internet do Senado Federal. 
Gráfico 5

Frequência de Decretos-Lei e Medidas Provisórias Editados entre 1937 e 2010

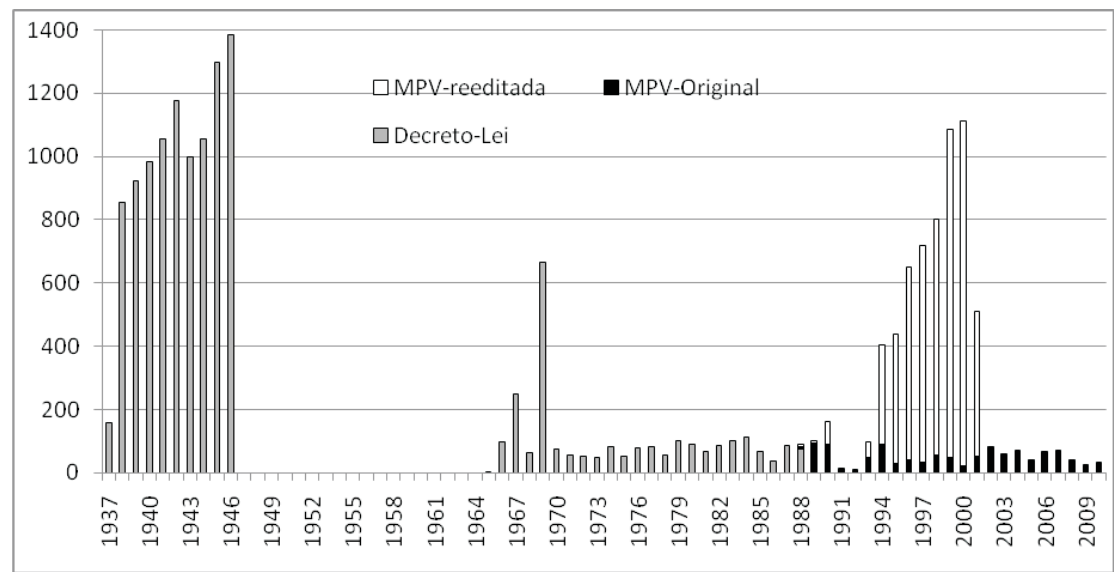

Fonte: Mecanismo de busca avançada sobre legislação do sítio da internet da Câmara dos Deputados (para os decretos-lei) e mecanismo de busca avançada do Sicon do sítio da internet do Senado Federal (para as MPV).

As medidas provisórias consistiriam em uma versão democrática dos antigos decretos-lei, os quais foram utilizados no Estado Novo - média anual de 988, entre 1937 e 1946 - e do governo militar - média anual de 268, entre 1966 e 1969, e de 74, entre 1970 e 1988. As MPV apresentaram uma média anual de 50, entre 1989 e 2010, considerando as edições originais (Gráfico 5). Até 2001, as MPV não convertidas em lei podiam ser reeditadas mensalmente, o que provocou ampliação geométrica nas proposições reeditadas - média anual de 600 MPV reeditadas entre 1993 e 2001. O ano que precedeu a mudança na tramitação das MPV foi o que produziu mais medidas, contudo, a quase totalidade foi de reedições, enquanto o número de medidas originais foi bem inferior ao de anos anteriores, indicando que a situação também prejudicava o Executivo. Após 2001, as alterações na tramitação das MPV permitiram aumento na média anual de edições originais para 54,6 , uma vez que, no período anterior (entre 1989 e 2001), a média anual havia sido de 47,4.

Informações sobre as "entradas" e "saídas" do sistema de produção legislativa em duas legislaturas recentes (entre 1999 e 2006) reforçam as particularidades de cada via legislativa. No que se refere à iniciação de proposições (Tabela 1), a via mais utilizada foi a ordinária $(87,9 \%)$, de menor hierarquia, destacando-se o elevado uso do projeto de lei ordinária $(81,8 \%)$. A via constitucional, que possui maiores exigências para apresentação e aprovação, foi acionada mais frequentemente $(7,7 \%)$ 
Cooperação, Liderança e Impasse entre o Legislativo e o Executivo na Produção...

Tabela 1

Proposições Legislativas que Iniciaram Tramitação na Câmara, Senado e Congresso Nacional entre 1999 e 2006, segundo Via Estratégica e Local de Apresentação

\begin{tabular}{l|c|c|c|c|c}
\hline Via Estratégica / & \multicolumn{5}{|c}{ Local de Apresentação } \\
\cline { 2 - 6 } Tipo de Proposição & Câmara & Senado & Congresso & Total & \% \\
\hline Constitucional / PEC & 1.140 & 506 & - & 1.646 & 7,7 \\
Complementar / PLP & 717 & 235 & - & 952 & 4,4 \\
Ordinária / PL & 14.584 & 2.970 & - & 17.554 & 81,8 \\
Ordinária / PLN & - & - & 783 & 783 & 3,7 \\
Ordinária / MPV & - & - & 512 & 512 & 2,4 \\
Ordinária (subtotal) & 14.584 & 2.970 & 1.295 & 18.849 & 87,9 \\
\hline Total & $\mathbf{1 6 . 4 4 1}$ & 3.711 & $\mathbf{1 . 2 9 5}$ & $\mathbf{2 1 . 4 4 7}$ & $\mathbf{1 0 0 , 0}$ \\
\hline \% & 76,7 & 17,3 & 6,0 & 100,0 & \\
\hline
\end{tabular}

Fonte: Banco de dados do estudo com base no Sistema de informações legislativas (Sileg) da Câmara dos Deputados, Prodasen do Senado Federal e sítio da internet do Planalto.

Legendas: PEC - proposta de emenda à Constituição; PLP - projeto de lei complementar; PL - projeto de lei ordinária; PLN - projeto de lei do Congresso Nacional; MPV - medida provisória.

que a complementar $(4,4 \%)$. A Câmara destacou-se como casa iniciadora $(76,7 \%)$, mas o Senado contribuiu com $17,3 \%$ do total de proposições e, considerando apenas as proposições iniciadas na própria casa, apresentou maiores proporções de uso das vias de maior hierarquia que a Câmara: $13,6 \%$ contra $6,9 \%$, no caso da constitucional, e 6,3\% contra $4,4 \%$, no da complementar.

O estereótipo de casa revisora, geralmente atribuíd do ao Senado, não se confirmou no caso da via constitucional; pelo contrário, este enviou no período 48 proposições para revisão da Câmara, enquanto esta enviou 20 para a revisão do Senado. Na via complementar, os quantitativos se assemelharam ${ }^{9}$, e na ordinária, a Câmara enviou mais projetos para revisão (903 contra 602); mesmo assim, o Senado apresentou considerável atividade, correspondendo a $73,3 \%$ do quantitativo produzido pela Câmara nessa via.

Sobre os resultados finais da tramitação nas vias (Tabela 2), os vetos totais apostos por presidente foram pouco frequentes $(0,2 \%$ das proposições apresentadas) e cerca de um terço das proposições ainda tramitavam em março de 2009 (exceto nas matérias de iniciativa exclusiva do Executivo, em que apenas 10,2\% ainda tramitavam, mas com força de lei, no caso da MPV, e nenhuma, no caso do PLN, indicando uma rápi- 
Fabio de Barros Correia Gomes

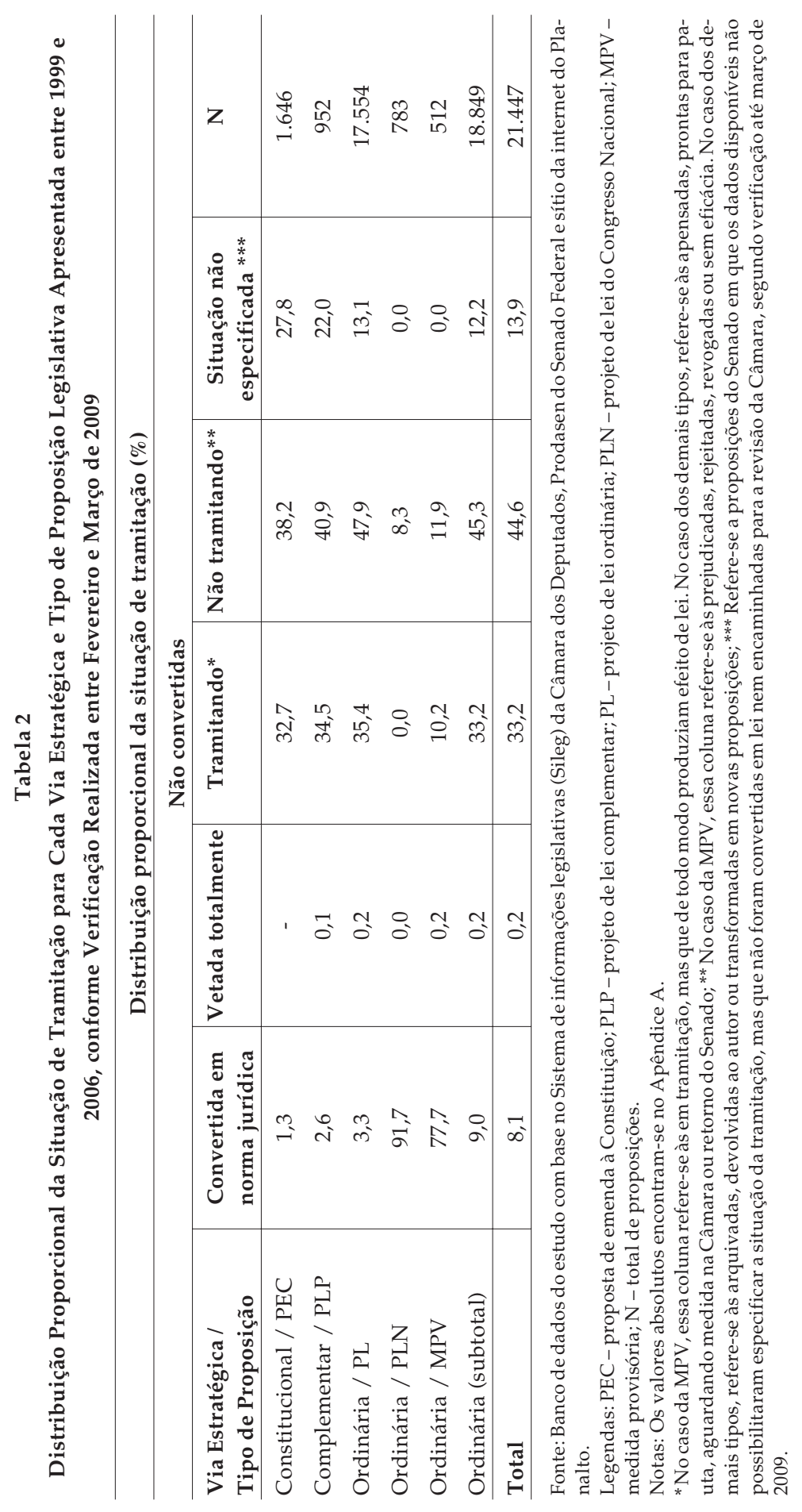


da resolução para esses tipos). Quanto ao resultado que indica o sucesso da tramitação (Tabela 2), 8,1\% de todas as proposições foram transformadas em norma legal, mas os resultados em cada via foram bastante diferenciados.

As taxas de sucesso (de conversão em norma) apresentaram gradação por via. Foram de 9,0\% para a ordinária, 2,6\% para a complementar e $1,3 \%$ para a constitucional. Considerando os tipos de proposição da via ordinária, os dois exclusivos do Executivo obtiveram taxas muito elevadas $(91,7 \% \text { para os PLN e 77,7\% para as MPV) })^{10}$, enquanto o PL, utilizado por ambos os poderes, alcançou 3,3\% (ainda assim, superior à taxa da via complementar).

Além das diferenças na eficiência relativa das vias e de seus tipos de proposição, também variaram os quantitativos de normas geradas em cada uma delas. Das proposições analisadas, foram sancionadas ou promulgadas: 21 emendas à Constituição, 25 leis complementares e 1.699 leis ordinárias, totalizando 1.745 normas jurídicas. No caso da via ordinária, a maior eficiência das MPV e dos PLN foi responsável pela produção de $65,7 \%$ das leis ordinárias, embora estes tipos tenham representado apenas 6,9\% das proposições iniciadas nessa via. De todo modo, mesmo com menor eficiência, os numerosos PL chegaram a produzir mais leis (583) que as MPV $(398)^{11}$.

Enfim, as especificidades das vias, de seus tipos de proposições e dos resultados quantitativos associados reforçam a relevância da análise desagregada de cada via legislativa na análise da relação entre os poderes, considerando ambas as casas legislativas.

\section{AGENDAS DOS PODERES E DESEMPENHO DE SEUS ATORES}

Para responder aos questionamentos sobre segmentação da agenda e dominância na interação entre os poderes, foram consideradas proposições apresentadas entre 1999 e 2006. Aquelas iniciadas pelo Legislativo foram as mais numerosas em todas as vias (mais de $95 \%$ em cada uma delas) ${ }^{12}$, mesmo na ordinária, em que o Executivo dispõe de três tipos de proposição. Isso contraria a percepção de que os parlamentares teriam interesses limitados a temas particularistas. Em termos absolutos, o volume elaborado por deputados foi superior ao dos demais atores $^{13}$. Contudo, a comparação do esforço propositivo em cada casa indicou uma atividade relativamente maior dos senadores em todas as vias. A atividade foi maior na via ordinária $(47,8$ projetos por senador e 
29,7 por deputado), seguindo-se a via constitucional (6,2 projetos por senador e 2,2 por deputado) e a complementar (2,9 projetos por senador e 1,3 por deputado).

Quanto ao conteúdo das proposições, a Tabela 3 sintetiza dados sobre as áreas de política dos projetos que compuseram a agenda apresentada entre 1999 e 2006 e a provada em cada via. Tanto quando se utiliza a perspectiva dos projetos que tramitaram no Senado, quanto aquela dos que tramitaram na Câmara, percebe-se a existência de especializações temáticas em cada via legislativa e que são similares nas duas casas. Por exemplo, a área político-institucional contribuiu consideravelmente com a agenda apresentada na via constitucional, reduzindo a participação progressivamente nas vias de menor hierarquia. No caso da área econômica, a via complementar se sobressaiu. Em geral, a área social incluiu-se entre as duas áreas mais frequentes em todas as vias, mas na via ordinária respondeu pela maioria da agenda. A área administrativa ocupou a terceira posição de frequência em quase todas as vias e a sobre homenagens ou simbólicos foi virtualmente inexistente nas vias de maior hierarquia, ocupando as últimas posições na via ordinária.

Alguma diferenciação na agenda considerada em cada casa também é perceptível: as áreas político-institucional e administrativa apresentaram proporções maiores no Senado, enquanto a área social foi prevalente na Câmara, em todas as vias (Tabela 3$)^{14}$.

O Gráfico 6 indica que deputados e senadores apresentaram mais propostas que o Executivo em todas as áreas de política, em todas as vias. Na via constitucional, a área social foi a mais frequentemente abordada pelo Executivo ${ }^{15}$. Também no que se aprovou da agenda nessa via a área social foi privilegiada, mas com a participação do Executivo e dos parlamentares, com destaque para os senadores (Gráfico 6). Nas leis ordinárias produzidas a partir de PL de deputados e senadores, quase a metade tratava de temas sociais $(47,2 \%$ de 345$)$, chegando a $56 \%$ entre as 191 leis de autoria do Executivo. Mesmo entre as 512 medidas provisórias, os temas sociais (41\%) superaram os temas econômicos (37\%) e os administrativos (22\%).

Uma observação marcante foi que as proporções das áreas de política presentes nas normas produzidas não corresponderam às proporções das áreas nas proposições que ingressaram nas casas (Tabela 3 e Gráfico 6). Por exemplo, a área social ganhou destaque quantitativo na pro- 
Cooperação, Liderança e Impasse entre o Legislativo e o Executivo na Produção...

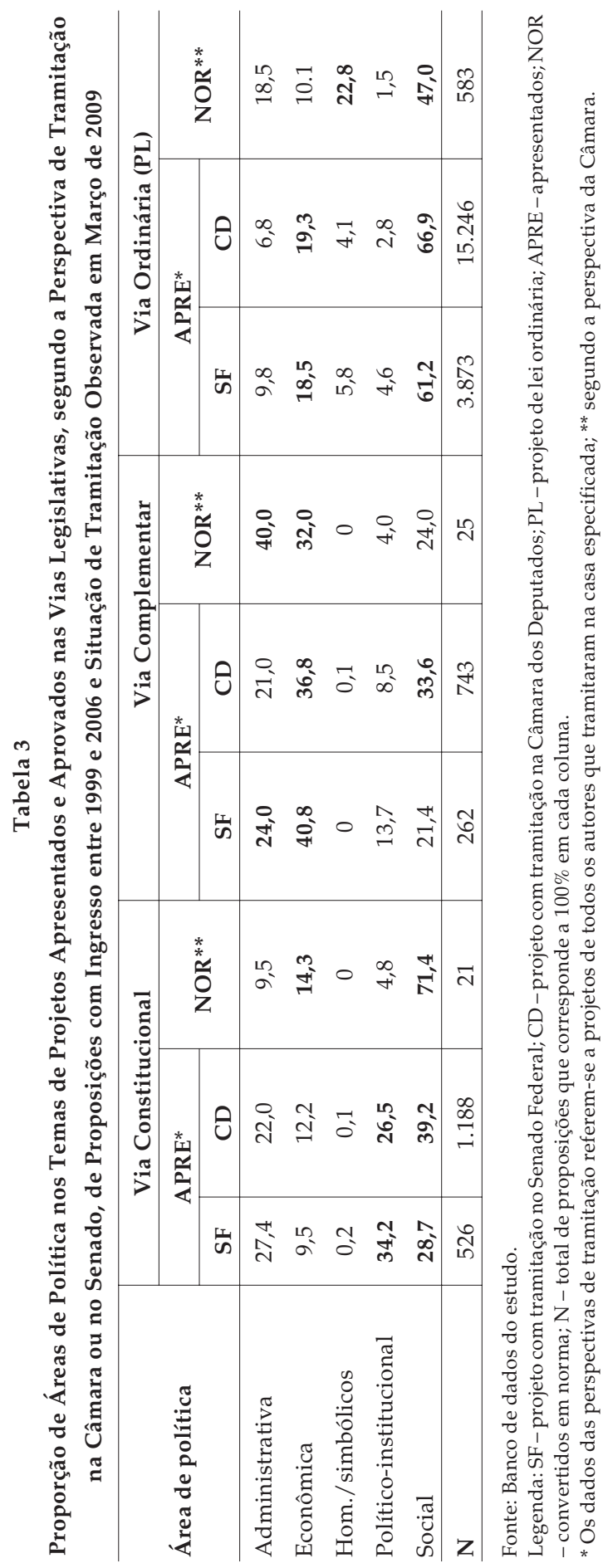


Fábio de Barros Correia Gomes

\section{Gráfico 6}

Distribuições de Proposições Legislativas, com Ingresso na Câmara, Iniciadas entre 1999 e 2006, segundo Autoria, Área de Política, Situação de Conversão em Norma (até março de 2009) e Via Legislativa

Via Constitucional
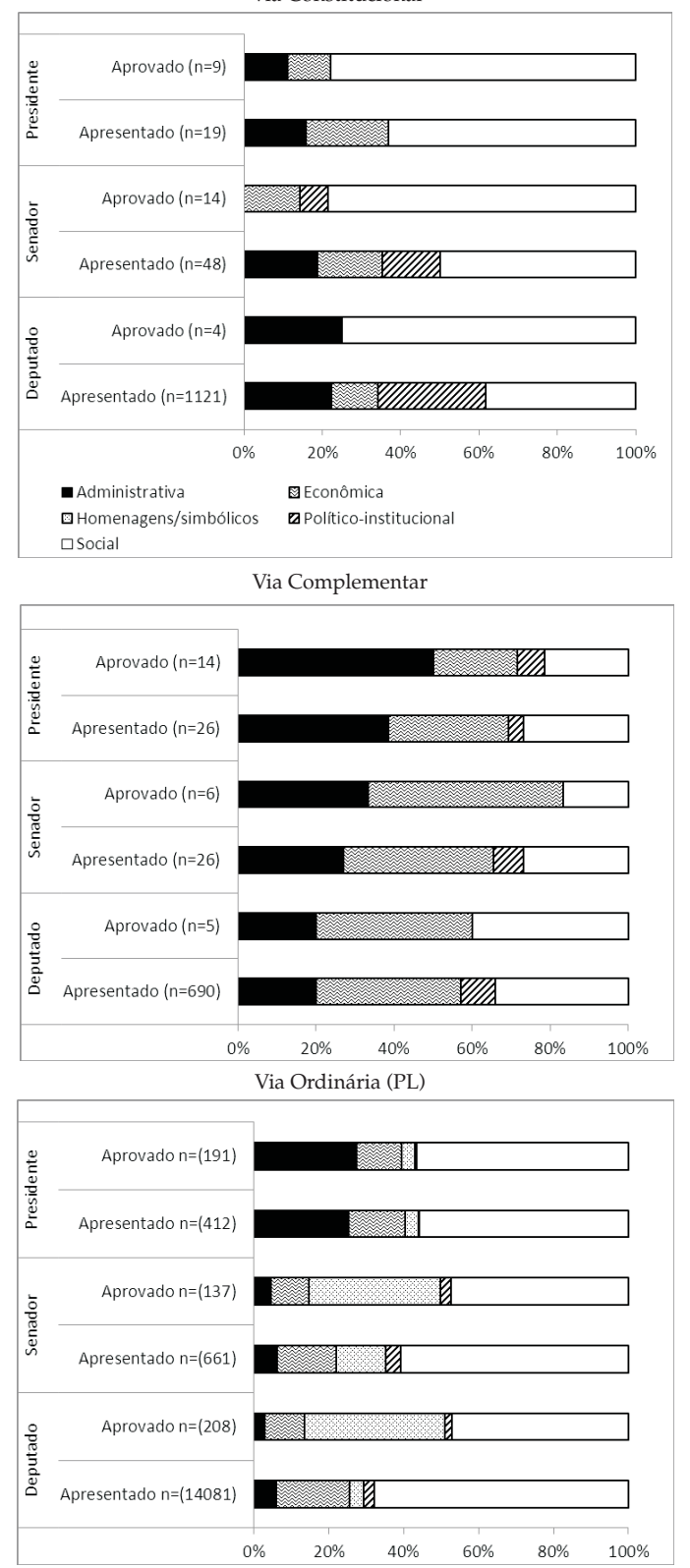

Fonte: Sistema de informações legislativas (Sileg) da Câmara dos Deputados. Banco de dados do estudo. 
dução da via constitucional; a área administrativa, na da via complementar; e a área de homenagens ou simbólicos, na da via ordinária. A implicação é que a agenda "aprovada" pelo Congresso não reflete proporcionalmente a que foi "apresentada".

Embora a elevada produção de leis ordinárias sobre temas de homenagens ou simbólicos (22,8\% do total de 583 leis provenientes de PL) reduzam o peso da relevância do que é produzido nessa via e sob a influência do Legislativo (autor de 94,7\% das leis dessa área), este Poder iniciou mais leis provenientes de PL que o Executivo também nas áreas econômica (61\% de 59 leis), político-institucional ( $88,9 \%$ de 9 leis) e social (59,5\% de 274 leis). Apenas na área administrativa o Executivo predominou (48,1\% de 108 leis), em função de sua competência legislativa exclusiva ${ }^{16}$. Assim, além da expressão de prováveis interesses particularistas, o Legislativo também atuou com destaque em políticas de interesse mais amplo.

Essa variedade de interesses e os resultados obtidos em área como a econômica sugerem a existência de especialização técnica no Legislativo. Entretanto, as comissões apresentaram baixa atividade propositiva de autoria própria nas vias de maior hierarquia (apenas 4 PEC e 10 PLP de 1999 a 2006), sendo um pouco maior na ordinária (198 PL, com destaque para a Comissão de Legislação Participativa, que contribuiu com $37,9 \%$ dos projetos provenientes de comissões). A via ordinária foi a única em que projetos de comissões foram convertidos em lei (em uma proporção de 2,3\%), exemplificando mais um dispositivo da Constituição de 1988 que vem amadurecendo ${ }^{17}$.

Sobre o desempenho dos atores, os achados reforçam a já conhecida predominância do Executivo na autoria da produção legal, mas em uma proporção menor (76,9\% das 1.699 normas produzidas na via ordinária e $76,1 \%$, considerando todas as 1.745 normas produzidas em todas as vias) que os $86 \%$ referentes aos meados da década de 1990. As taxas de sucesso e de dominância do Executivo foram inversamente proporcionais ao nível hierárquico das vias estratégicas (Tabela 4). Essa gradação também ocorreu para o conjunto de todos os autores, mas os patamares de sucesso do Executivo foram bem superiores (Tabela 4 ).

$\mathrm{Na}$ via constitucional, o desempenho do Executivo caracterizou-se pela apresentação de poucas propostas (1,6\% de 1.188 PEC), priorizando temas que comprometiam o orçamento federal (6 das 7 emendas 
constitucionais de autoria do Executivo comprometiam o orçamento). Não sofreu uma única rejeição formal. O destaque alcançado pelo Senado nessa via (com taxas de sucesso maiores que as dos deputados e com quantitativo de emendas constitucionais exitosas superior até mesmo que o do Executivo) afasta um papel apenas de Casa Reviso$\mathrm{ra}^{18}$. Também sugere uma maior especialização e protagonismo (provavelmente pela atuação mais ágil de suas comissões) em uma via, que, a princípio, aborda temas de alta relevância ${ }^{19}$, e reforça demandas por consideração específica desses autores nos estudos de produção legislativa.

Na via complementar, o papel dos senadores foi similar ao dos deputados (estes foram autores de cinco leis e aqueles, de seis). A influência da coalizão continuou predominante, mas desta feita por atuação mais direta do Executivo (autor de 56\% das leis complementares, 64,3\% delas com comprometimento do orçamento federal), conforme esperado pelos recursos permitidos a esse ator nessa via (principalmente a urgência e o veto presidencial). Entretanto, a produção final da coalizão não alcançou os mesmos níveis que na via constitucional, pois a oposição obteve êxitos superiores aos dos parlamentares da coalizão, inclusive em projetos com envolvimento orçamentário ${ }^{20}$. Os autores do Legislativo produziram mais leis complementares em temas econômi$\cos ^{21}$ e o Executivo, na área administrativa ${ }^{22}$.

Na via ordinária, os deputados produziram 1,5 vez mais leis que os senadores $^{23}$, com destaque para os temas sociais $(47,1 \%$ de 208$)$ e os de homenagens ou simbólicos (37,5\% de 208), sugerindo uma permeabilidade maior desses atores às demandas da sociedade, além dos interesses particularistas. Ressalve-se que, apesar do maior envolvimento dos senadores com os relevantes temas da via constitucional, na ordinária também se dedicaram à área de homenagens ou simbólicos e, até, obtiveram maior taxa de sucesso (39\% de 123 PL) que os deputados (14,8\% de 526 PL).

Observe-se que o desempenho do Executivo na via ordinária, no tipo de proposição em que há concorrência de iniciativa com os parlamentares, o PL, a taxa de sucesso chegou a ser inferior à obtida na via complementar (Tabela 4). Contudo, o melhor desempenho do Executivo nessa via foi garantido pelas elevadas taxas das MPV e PLN. As taxas de dominância do Executivo na produção de cada via seguiu a mesma 
tendência hierárquica. Novamente, observa-se menor "dominância" com relação aos PL (Tabela 4).

Esses dados contrariam a tese da predominância do Executivo, pelo melhor desempenho do Legislativo na via de maior nível de hierarquia (foi autor de $66,7 \%$ das emendas constitucionais, com destaque para a produção originada no Senado) e também no caso dos PL (foi o autor mais prevalente - 59,2\% -, com destaque para a atuação da Câmara na área social). Entretanto, antes de se supor uma predominância do Legislativo nessas situações, os dados sobre o desempenho da coalizão indicam algo diferente. A taxa de dominância da coalizão mostrou-se elevada em todas as vias $(89,2 \%$ na via ordinária, $72,0 \%$ na complementar e $90,5 \%$ na constitucional), inclusive quebrando o padrão hierárquico pelo elevado rendimento apresentado na via constitucional (chegando a $100 \%$ das emendas constitucionais com comprometimento do orçamento federal $)^{24}$. Assim, o predomínio na produção legislativa, considerando os níveis de relevância das propostas, ocorreria por atuação da coalizão em todas as vias legislativas, por meio das iniciativas compartilhadas entre o Executivo e os parlamentares da base.

O comprometimento do orçamento federal coloca-se como relevante fator de atração dos esforços da coalizão, sendo, potencialmente, capaz de influenciar a interação entre os poderes. Esteve presente em $47,6 \%$ das normas produzidas na via constitucional e $60 \%$ na complementar. Na via ordinária, as leis provenientes de PL não foram analisadas quanto a esse tipo de comprometimento, mas as provenientes de PLN e MPV indicam que, nessa via, pelo menos 45,7\% das leis comprometiam o orçamento federal. Esse comprometimento foi observado no subconjunto de proposições relacionadas à saúde que tramitaram na Câmara. Entre as PEC, 37,2\% o apresentavam. No grupo de ações e serviços de saúde essa proporção chegou a 59,6\%; no de benefícios, a $36,5 \%$; no de redução de riscos, a 14,8\%; e no de direitos, a nenhum envolvimento. Os dois últimos grupos não foram objeto de proposta direta do Executivo. Nas poucas vezes em que o Executivo iniciou proposição relacionada à saúde nessa via priorizou temas no grupo de ações e serviços de saúde ( 5 das 6 PEC) e em $83,3 \%$ de suas PEC havia comprometimento do orçamento federal. Das 9 PEC exitosas, 6 (67\%) apresentavam impacto no orçamento federal.

Entre os PLP relacionados à saúde, 45,5\% apresentavam comprometimento do orçamento federal, sendo que no grupo sobre "ações e servi- 
ços de saúde" essa proporção chegou a 63,8\%; no de "benefícios", a $39,5 \%$ e no de "redução de riscos", a 18,2. O Executivo apresentou apenas 3 PLP, todos eles no primeiro grupo temático, com envolvimento do orçamento federal e no período entre 1999 e 2002.

Em suma, foram encontrados indícios de que a agenda dos poderes não é segmentada; que os parlamentares possuem interesses específicos, mas também amplos; que o nível de exigência das regras determina taxas de sucesso que são inversamente proporcionais à complexidade das vias; e que a dominância dos atores varia nestas. Nem sempre a autoria do Executivo predominou, mas a da coalizão foi incontestável.

\section{Tabela 4}

Distribuição de Taxas de Sucesso e de Dominância, segundo as Vias Legislativas, de Proposições em todos os Temas de Política, de Autores Selecionados, com Ingresso na Câmara dos Deputados entre 1999 e 2006 e Situação de Tramitação Observada em Março de 2009

\begin{tabular}{l|c|c|c|c}
\hline \multirow{2}{*}{ Via } & \multicolumn{2}{|c|}{ Taxas de Sucesso (\%) } & \multicolumn{2}{c}{ Taxa de Dominância (\%) } \\
\cline { 2 - 5 } Constitucional & Todos autores & Executivo & Executivo & Coalizão \\
Complementar & 1,3 & 36,8 & 33,3 & 90,5 \\
Ordinária & 2,6 & 53,8 & 56,0 & 72,0 \\
PL* & 9,0 & 76,6 & 76,9 & 89,2 \\
MPV & 3,3 & 46,6 & 32,8 & 76,9 \\
PLN & 77,7 & 77,7 & 100,0 & 100,0 \\
\hline
\end{tabular}

Fonte: Banco de dados do estudo.

* No caso dos PL, foi considerado o ingresso na Câmara no período do estudo.

\section{Utilização de Recursos nas Vias Legislativas}

O desempenho dos atores pode ser compreendido pela observação do acesso aos recursos do sistema, para influenciar no tempo de tramitação de proposições ou para modificar seu conteúdo.

Quanto ao tipo de apreciação dos PL (único tipo em que é possível a aprovação de uma proposição conclusivamente pelas comissões, sem a consideração pelo plenário) convertidos em lei, o plenário definiu $39,1 \%$, e as comissões, $58,3 \%$. As comissões definiram $70,7 \%$ das leis de deputados e $81,8 \%$ das de senadores. O plenário definiu $66,5 \%$ das leis do Executivo e 51,1\% das de outros autores (Judiciário). A apreciação conclusiva pelas comissões predominou na área de homenagens ou 
simbólicos $(91,0 \%)$ e apresentou alguma vantagem nas áreas social $(53,6 \%)$, econômica $(50,8 \%)$ e político-institucional $(44,4 \%)$. O plenário destacou-se na produção de leis na área administrativa $(63,9 \%)$.

Com relação ao regime de urgência, na via complementar, foi utilizada em 3,4\% dos 743 PLP, mas com variação segundo autoria: em 76,9\% dos 26 PLP do Executivo (em 11 casos por requerimento de parlamentares a urgência "legislativa" - e em 9, solicitada pelo próprio presidente - a chamada urgência "constitucional"); em 30,8\% dos 26 PLP de autoria de senadores e em apenas 4,6\% dos 690 PLP de deputados. O efeito acelerador da urgência para conversão do PLP em lei complementar foi observado no caso da urgência constitucional (tempo médio de tramitação de 265,7 dias, bem menor que a média de 667,5 dias para o conjunto dessa via), contudo, a urgência requerida por parlamentares obteve média de 919,1 dias, superior à da via. Isso, aliado ao fato de que as leis complementares sem regime de urgência terem tramitado mais rapidamente (média de 347 dias) que as com urgência legislativa, sugerem que esta tenha sido empregada como um meio para colocar os temas na agenda de decisão.

Na via ordinária, o uso da urgência também foi associado à produção de leis de modo desigual entre os atores. Das 345 leis ordinárias de autoria do Legislativo provenientes de PL, 18,6\% foram beneficiadas pela urgência, enquanto para os 191 leis ordinárias de autoria do Executivo o valor foi de 64,9\% (e destas, 64,5\% foram urgências legislativas). Além disso, a proporção de conversão em lei entre os projetos em regime de urgência na Câmara foi maior para o Executivo (75,2\% de 165 PL), que para os parlamentares (44,9\% de 49 PL de senadores e 5,7\% de 732 PL de deputados).

O esforço de modificação do conteúdo das proposições foi estudado em um subconjunto menor, o das proposições relacionadas à saúde, verificando-se um alto nível de participação do Legislativo. Na via constitucional, $77,8 \%$ das 9 emendas constitucionais relacionadas à saúde e $22,4 \%$ das 78 PEC arquivadas foram objeto de emenda substitutiva (tipo que geralmente produz alterações de maior abrangência) durante sua tramitação na Câmara. Na via complementar, as duas leis foram objeto de substitutivo. Na via ordinária, em 74,2\% das $66 \mathrm{MPV}$ convertidas em lei foram apresentadas emendas (em 9 casos foram mais de 100 emendas, e no mais extremo, 572 emendas). Em 58\% das MPV foi necessário elaborar um projeto de lei de conversão, indicando 
que o texto foi efetivamente modificado pelo Legislativo. Quanto aos projetos orçamentários relacionados à saúde, 37,8\% dos 82 PLN receberam substitutivo, contudo, houve diferenciação por relevância de conteúdo. O substitutivo foi usado em 90,5\% dos 21 PLN "orientadores" do orçamento, mas em 19,7\% dos 61 PLN sobre créditos extraordinários específicos.

As tentativas de modificações de conteúdo ao final da tramitação são apreciadas pela observação dos vetos presidenciais. Considerando o conjunto total (todos os temas), a elevada proporção de vetos parciais nas 25 leis complementares (44\%) indica que o Executivo não conseguiu influenciar a tramitação das matérias como desejado ou, ainda, a necessidade de realizar correções formais. As próprias leis complementares de autoria do Executivo sofreram vetos parciais $(42,9 \%$ de 14). Nenhum desses vetos foi deliberado pelo Congresso antes de 2004, contrariando as regras vigentes, e nenhum deles foi derrubado.

Os 38 vetos totais ocorridos na via ordinária (em todos os temas) também sugerem que nem sempre a coalizão consegue controlar a tramitação dos projetos. Nesses casos, em nenhum havia comprometimento orçamentário federal e não havia concentração maior de PL da oposição $(47,4 \%)$. Sua associação com o tipo de apreciação conclusiva pelas comissões $(76,3 \%)$ sugere que o monitoramento da coalizão não tenha atuado tão eficientemente nessas instâncias e nessa via (talvez pelo reduzido nível de conflito distributivo), ou que simplesmente não tenha sido capaz de impor seus interesses. De todo modo, essas propostas (inclusive as da coalizão) não prosperaram, pois, como na via complementar, os vetos, em geral, foram decididos tardiamente e nenhum foi derrubado.

Sobre a finalização da tramitação das proposições, os tempos médios de tramitação das proposições convertidas em norma confirmam a vantagem para as do Executivo nas vias em que o recurso da urgência está disponível - complementar e ordinária - (Tabela 5). A expectativa de um tempo mais prolongado na via constitucional (pelas maiores exigências para aprovação) não se confirmou. Pelo contrário, nessa via, o Executivo obteve média de 315 dias (quase três vezes mais rápido que os projetos do Legislativo e mais lento apenas que proposições na via ordinária - as MPV, com média de 91 dias, e os PLN, com média de 63 dias). Nessa e nas demais vias os tempos médios das leis iniciadas pela coalizão foram mais rápidos que os da oposição (Tabela 5). 
Cooperação, Liderança e Impasse entre o Legislativo e o Executivo na Produção...

Tabela 5

Distribuição de Tempos Médios de Tramitação, Segundo as Vias Legislativas, de Proposições Convertidas em Norma Legal em Todos os Temas de Política, de Autores Selecionados, com Ingresso na Câmara dos Deputados entre 1999 e 2006 e Situação de Tramitação Observada em Março de 2009

\begin{tabular}{l|c|c|c|c|c}
\hline \multirow{2}{*}{ Via } & \multicolumn{5}{|c}{ Tempo Médio de Tramitação (dias) } \\
\cline { 2 - 6 } & Executivo & Deputado & Senador & Coalizão & Oposição \\
\hline Constitucional & 315 & 985 & 1.323 & 892 & 1.382 \\
Complementar & 520 & 1.093 & 656 & 553 & 961 \\
Ordinária & $*$ & $*$ & $*$ & $*$ & $*$ \\
PL & 451 & 1064 & 1129 & 788 & 1.134 \\
MPV & 91 & - & - & - & - \\
PLN & 63 & - & - & - & - \\
\hline
\end{tabular}

Fonte: Banco de dados do estudo.

* Não calculada (ver os dados para cada tipo de proposição da via).

A finalização das proposições que não obtiveram êxito mostrou-se diferente de acordo com a via e a autoria. A análise de fluxo das proposições relacionadas à saúde indicou que mecanismos de não decisão, como o arquivamento ao final das legislaturas (devido à falta de parecer de comissão), foram frequentes nas vias constitucional e complementar (73,8\% e 76,6\%, respectivamente). Em todas as vias, os projetos do Executivo raramente foram rejeitados ou arquivados ao final da legislatura, pois ou foram retirados ou prejudicados pela deliberação de outra proposta $(60,0 \%$ e $35,0 \%$, respectivamente, no caso dos 20 PL do Executivo que foram arquivados). Os $32 \mathrm{PL}$ arquivados de senadores sofreram destino diferente: 75,0\% foram formalmente rejeitados. Os 25 PL arquivados de autoria de comissões da Câmara foram predominantemente arquivados ao final da legislatura (84,0\%). Em uma amostra de 64 PL arquivados de autoria de deputados, verificou-se que, entre os que tramitaram com urgência, $87,5 \%$ foram prejudicados, e entre os que tramitaram sem urgência, 52,9\% foram arquivados ao final da legislatura.

Em resumo, o controle dos recursos disponibilizados pelas regras institucionais ofereceram vantagens ao Executivo e à coalizão. Até mesmo o modo como as proposições foram arquivadas demonstra o diferencial no acesso aos recursos pelos diferentes atores. A urgência efetivamente acelerou as propostas do Executivo e, no caso do Legislativo, comportou-se como mecanismo para colocar matérias na pauta de decisão. O Executivo focou a atuação no plenário, e ao Legislativo restou 
a utilização das comissões, que possuem um fluxo mais lento de decisão.

Contudo, o Legislativo utilizou-se amplamente dos recursos para modificar os projetos do Executivo em todas as vias. Como último recurso para controlar o conteúdo, o Executivo valeu-se dos vetos parciais e totais, que em nenhuma ocasião, no período estudado, foi derrubado pelo Legislativo. Para tanto, contou com a colaboração do responsável pela pauta do Congresso, pois as deliberações sobre os vetos só ocorreram anos após suas aposições; exemplificando, o poder da atuação das coordenações das instâncias de decisão na definição da pauta de deliberação e, até, do produto das vias.

\section{INTERAÇÕES ENTRE OS PODERES}

A cooperação entre os poderes foi observada no caso das tramitações de projetos de leis orçamentárias do Executivo por meio de PLN. O conteúdo foi predominantemente de baixo nível de conflito: rotineiras aberturas de créditos extraordinários (por exemplo, em 75\% dos PLN relacionados à saúde). Na apreciação, foi observada maior utilização de recursos de aceleração que de obstrução. A atividade de modificação dos PLN pelos parlamentares foi considerável (talvez isso nem sempre indique existência de conflito, podendo refletir colaboração na construção da proposta). Na conclusão, o tempo médio de conversão em lei foi o menor de todo o sistema (menor ainda que o das medidas provisórias) - apenas 63 dias -, e a taxa de sucesso foi a maior (quase todas foram convertidas em lei).

Essa cooperação estaria institucionalizada, por meio das regras que permitem dar solução regular e rápida a questões orçamentárias, em um menor número de instâncias de decisão e com rito especial. Quantitativamente falando, apenas esse tipo de proposição é suficiente para que a cooperação seja indicada como um dos tipos de interação mais frequente (devido ao peso dos PLN na produção da via ordinária e na produção total, correspondendo a $41 \%$ desta), mas de modo algum é sugerido que isso indique que o sistema seja cooperativo, pois desprezaria a questão da relevância das proposições, que é uma das principais contribuições da distinção das vias legislativas. A maior relevância desse destaque é que a literatura, ao considerar valores agregados de leis produzidas, termina por adicionar, inadvertidamente, todo esse 
volume de leis derivadas do PLN às evidências que justificariam a predominância do Executivo, o que não parece ser adequado.

Outro exemplo de cooperação entre os poderes seria a obtenção do regime de urgência (o que depende de votação da maioria) que ocorreu em projetos de lei complementar da oposição convertidos em norma, inclusive com envolvimento orçamentário federal. Quanto à liderança da coalizão, há indícios de um peso significativo desse tipo de interação em todas as vias. Os conteúdos que envolvem o conflito distributivo e afetam a governabilidade, como o comprometimento do orçamento federal, aparentam atrair os esforços do Executivo e sua base, como se observou nas duas vias de maior hierarquia. Na via constitucional, todas as emendas constitucionais com comprometimento orçamentário federal a provadas foram de autoria da coalizão. Outro indício foi a identificação de gradação do impacto orçamentário dos grupos temáticos da saúde e que os grupos com maior comprometimento se associaram às áreas de maior interesse do Executivo. Na fase de apreciação, foi observada vantagem para a coalizão na utilização de recursos como a urgência, com efetiva aceleração de suas proposições, que obtiveram os menores tempos médios de tramitação. Mesmo na via constitucional, em que não há regime de urgência, provavelmente por atuação dos coordenadores de instâncias de decisão. Na fase de conclusão, a liderança se expressa por meio das expressivas taxas de sucesso e de dominância da coalizão, obtidas pelo compartilhamento da autoria entre Executivo e membros de sua base no Legislativo, particularmente do Senado.

A liderança do Legislativo não pode ser sugerida apenas pelos significativos achados de predominância do Legislativo como autor de mais normas na via constitucional e também nas leis ordinárias provenientes de PL. Novamente, são necessárias considerações qualitativas. No caso, a constatação de que a coalizão obteve elevadas taxas de dominância em todas as vias torna improvável uma predominância ou liderança autônoma do Legislativo nessas situações, sendo mais coerente que esse achado reflita a lógica do presidencialismo de coalizão. Nem mesmo uma esperada liderança em projetos da área político-institucional e de homenagens ou simbólicos (aparentemente menos relevante e de menor interesse para a coalizão, associada à a provação conclusiva pelas comissões, com autoria quase que exclusiva do Legislativo, sendo, inclusive, a área temática em que deputados e senadores alcançaram suas maiores taxas de sucesso) pôde ser caracterizada, pois apesar 
da maior quantidade de leis de autoria do Legislativo, também nessas áreas a coalizão predominou. De todo modo, persiste a potencialidade de ocorrência desse tipo de interação, que pode ainda ser captada em estudos qualitativos de áreas de políticas específicas.

Situações de impasse foram evidentes nos casos de veto total nas vias complementar e ordinária (geralmente após longas tramitações), mas a ausência de comprometimento orçamentário nesses casos demanda maior investigação. Um veto total na via complementar em PLP de autoria da oposição na área político-institucional (sobre eleições municipais) sugere a relevância da governabilidade no conflito entre os poderes. Como nenhum dos vetos foi derrubado, apenas estudos de caso poderiam avaliar se os impasses foram superados por meio de outras proposições.

De modo geral, foi fortalecida a hipótese de relação entre o impacto orçamentário potencial da legislação na conformação da interação entre os poderes, de forma que, quanto maior tal impacto, maior a mobilização do Executivo e da coalizão de governo, com maior nível de conflito, expresso no uso de recursos nas várias fases da tramitação.

\section{CONCLUSÕES}

Os dados sugerem que o sistema funciona com regularidades compatíveis com o marco institucional adotado, como as observadas: nos padrões de apresentação das proposições; nas suas probabilidades de dominância e de sucesso, segundo autoria; na aplicação de recursos estratégicos e nos resultados finais da tramitação. $\mathrm{O}$ arranjo institucional tem propiciado um fluxo regular e consistente de produção de leis em vias estratificadas por nível de relevância do conteúdo.

As taxas de sucesso inversamente hierarquizadas, segundo a complexidade das vias, indicam que há maior facilidade para aprovação de políticas em vias de menor hierarquia. As altas taxas de sucesso dos dois tipos de proposição de uso exclusivo do Executivo (ambos na via ordinária), particularmente nas matérias de conteúdo orçamentário, sugerem que o sistema está orientado para oferecer ao Executivo as condições necessárias de governabilidade no contexto do presidencialismo de coalizão. Oferece tanto diretrizes normativas (visando o equilíbrio orçamentário e a equidade social), quanto os meios estratégicos para a solução dos problemas nacionais, mais intensamente na via ordinária. Nesse contexto, o Legislativo retém poder suficiente para ofe- 
recer a palavra final sobre a aprovação das matérias em qualquer via, particularmente na constitucional. Isso é relevante, principalmente quando se considera que grande parte das políticas públicas estão "constitucionalizadas".

O sistema mostrou-se dinâmico, sendo identificados progressivos amadurecimentos de iniciativas institucionais que visam o fortalecimento das comissões permanentes das casas e, logo, de sua capacidade para orientar políticas públicas. Todavia, não se pode afastar a influência de certo nível de informalidade na aplicação de algumas importantes regras (como as relacionadas à tramitação de medidas provisórias e à consideração de vetos presidenciais), que possuem influência em matérias de elevada relevância.

Ainda assim, regras formais importam no Brasil, de modo que não é plausível explicar o "paradoxo brasileiro" com base apenas em informalidades nem argumentar que essa seria uma característica útil a democracias emergentes. Os padrões observados reafirmam o papel das regras na produção de políticas, sugerindo que o sistema não é caótico e que as instituições políticas do país têm possibilitado a superação de impasses na produção de políticas públicas de modo negociado no período posterior à Constituição Federal de 1988.

A análise da agenda legislativa, que incorporou todas as proposições apresentadas em um determinado período e em todas as instâncias de decisão do Congresso, permitiu a identificação de especializações temáticas nas vias legislativas, com alguma variação na intensidade com que temas foram abordados nas duas casas (embora os conteúdos tenham sido semelhantes em cada uma das vias).

Relevantes para reflexões sobre representatividade foram os achados que contrariam a percepção de que os parlamentares teriam interesses legislativos que buscam predominantemente a satisfação de interesses de grupos, em oposição aos amplos interesses da sociedade. Tal percepção foi abalada pelo achado de que o Legislativo foi o mais ativo propositor de projetos em todas as vias, participando, em geral, com mais de $90 \%$ das proposições, com destaque para a atividade do Senado (principalmente nas vias de maior hierarquia), em termos relativos ao número de parlamentares, e para a da Câmara, em termos dos quantitativos totais. Esses achados esclarecem artefato produzido por análises prévias que priorizavam apenas as proposições convertidas em norma. Vale ressaltar que a magnitude da atividade propositiva do Le- 
gislativo brasileiro é similar àquela registrada na América Latina, por exemplo, parlamentares argentinos apresentaram dez vezes mais proposições que o presidente (Alemán e Calvo, 2008).

Os dados também se opõem à demarcação da agenda entre os poderes, coerente com a conclusão de Figueiredo e Limongi (2009) sobre a "fusão da agenda" substantiva do Executivo e de parte do Legislativo. O Executivo apresentou propostas na área social em todas as vias, e mesmo quando utilizou as medidas provisórias, atuou mais frequentemente nessa área. Entre os parlamentares, a área social foi a mais constante nas proposições da via ordinária ${ }^{25}$. Também houve uma maior produção de leis de parlamentares na área social nessa via, mas outras áreas de política se sobressaíram na sua produção nas demais vias, como nos PLP da área econômica.

A variedade de interesses dos parlamentares e os resultados obtidos em área como a econômica sugerem a existência de capacidade informacional no Legislativo. Contudo, foi baixa a produção de autoria de comissões permanentes (o que sugere pouca capacidade das comissões para orientar uma agenda legislativa autônoma), sobressaindo-se um pouco aquela proveniente da via ordinária.

Ainda que o Legislativo tenha se destacado na produção de normas de elevada hierarquia, também chamou atenção sua elevada proporção na área de homenagens ou simbólicos, indicando que os parlamentares possuem tanto interesses distributivistas (pela conexão eleitoral), quanto amplos (por exemplo, pela adesão ao programa da coalizão).

Outro achado de interesse com relação à agenda foi que as áreas das políticas iniciadas nas vias em ambas as casas não tiveram o mesmo peso na agenda efetivamente aprovada. Isso sugere que os mecanismos de centralização do processo decisório, já identificados na literatura, estejam facilitando o processo deliberativo (o que favorece a governabilidade), mas talvez o Congresso não esteja sendo capaz de influir nas políticas públicas como os representados desejam, com implicações para a qualidade da democracia.

Quanto às interações entre os poderes, foram observadas variações relacionadas a acessos diferenciados a recursos legislativos pelos atores. No nível agregado, em geral, os dados não se diferenciam dos achados originais de predominância quantitativa do Executivo na produção legislativa total (Figueiredo e Limongi, 1999). A estatística de que $86 \%$ da 
produção até meados da década de 1990 seria predominantemente de autoria do Executivo, foi confirmada nos estudos de Carneiro (2009), que considerou o período de 1988 a 2007, encontrando um valor de 79,7\%; muito próximo ao valor encontrado nesse estudo, de 76,9\% para o caso da via ordinária. Reafirma-se, desse modo, que o Legislativo não tem representado obstáculo à atuação do Executivo.

Contudo, o fato de o Executivo prevalecer na produção de lei por meio de seus tipos de proposição privativos, de escalão inferior, mas mais numerosos, tem levado a uma superestimação do domínio desse Poder e a uma desconsideração do presidencialismo de coalizão. Além disso, a intensa modificação produzida pelos parlamentares nas propostas do Executivo também indica que a predominância do Executivo não seria a única explicação viável para a compreensão da definição de políticas no Brasil, principalmente quando se considera a relevância das propostas (estratificadas em três vias).

As taxas de sucesso e de dominância do Executivo foram inversamente proporcionais ao nível hierárquico das vias, contrariando a tese da dominância quantitativa deste na via de maior hierarquia (em que o Legislativo foi autor de 66,7\% das emendas constitucionais, com destaque para a produção originada no Senado - sugerindo especialização no trabalho de suas comissões) e nas leis provenientes de PL (em que o Legislativo foi autor de 59,2\% dessas normas, com destaque para a atuação da Câmara na área social). Contudo, foi demonstrada dominância da coalizão em todas as vias, chegando a 89,2\% na via ordinária, 72,0\% na complementar e $90,5 \%$ na constitucional. Os achados relativos à forte dominância da coalizão no quantitativo e celeridade de normas produzidas em todas as vias são assimiláveis pela lógica de que o sistema está orientado para a promoção da governabilidade.

Além da liderança da coalizão, a observação sistêmica do funcionamento das vias legislativas também permitiu a coleta de indícios da ocorrência de outros tipos de interação entre os poderes, como a cooperação (particularmente no caso das muito frequentes leis orçamentárias) e o impasse. Esses achados ainda dependem de posterior aprofundamento qualitativo, principalmente quanto à ocorrência, no contexto atual, da liderança do Legislativo, embora a potencialidade permaneça, segundo as regras em vigor.

Considerando que o nível de conflito gerado por uma proposição é importante para motivar um maior envolvimento do Executivo e de sua 
base de apoio, é plausível supor que o comprometimento orçamentário federal exerça grande atrativo, pois o Executivo já se encontra fortemente restringido por dispositivos constitucionais em sua capacidade de direcionar novos gastos e é provável que resista a uma maior carga de obrigações. Brady e Volden (2006) destacaram a importância da distinção dos conteúdos de legislação com impacto orçamentário, o que se mostrou bem adequado ao caso brasileiro. Contudo, conteúdos não orçamentários que afetem a accountability, a governabilidade, ou, mais amplamente, a sua "capacidade governativa" - na expressão de Santos (1997) - também podem originar interações conflituosas. Em suma, sugere-se que o conflito distributivo e questões de governabilidade estejam na base dos variados tipos de interação entre os poderes no presidencialismo de coalizão brasileiro.

A utilização da abordagem sistêmica e estratégica, considerando o contexto histórico, atenuou a fragmentação da análise da agenda e facilitou a integração da análise das macrorrelações (entre instituições) e das microrrelações (entre os atores), que, analisadas separadamente, produziriam resultados díspares; mas que, quando qualificadas pelo marco institucional apresentado (fortemente baseado no arcabouço constitucional e na consideração do conflito entre os interesses sistêmicos e os estratégicos, gerado pelo conteúdo da política), mostraram-se parte de uma mesma dinâmica.

(Recebido para publicação em fevereiro de 2012)

(Reapresentado em agosto de 2012)

(Aprovado em outubro de 2012) 


\section{Cooperação, Liderança e Impasse entre o Legislativo e o Executivo na Produção...}

\section{NOTAS}

1. McGuire (2010) reconheceu o papel da democracia brasileira na implementação de programas de atenção primária à saúde que contribuíram para a redução da mortalidade infantil no país. Melo (2008) destacou as conquistas das políticas de educação e saúde. Langoni (2010) observou a agilidade com que as instituições brasileiras responderam à crise econômico-financeira mundial iniciada em 2008, em comparação com países europeus.

2. Carvalho e Gomes (2008) analisaram 15.246 projetos de lei ordinária (PL) apresentados na Câmara dos Deputados entre 1999 e 2006 e verificaram que, entre os convertidos em lei até março de 2007, 53,5\% eram de autoria do Legislativo e 38\%, do Executivo. Carneiro (2009) verificou que, entre outubro de 1988 e dezembro de 2007, o Legislativo iniciou $47,4 \%$ das leis ordinárias provenientes de PL e o Executivo, $42 \%$.

3. Amaral (2011) observou que a Câmara dos Deputados alterou 76\% PL apresentados entre fevereiro de 1995 e fevereiro de 1996, sendo as alterações feitas, em sua maioria $(67,9 \%)$, por meio de substitutivo. Cruz (2009) verificou que 73,3\% dos PL do Executivo, entre 1999 e 2006, foram objeto de emendas e que $60,2 \%$ foram efetivamente modificados pelas comissões da Câmara dos Deputados. Sobre os PL do Executivo, a autora verificou que $49 \%$ daqueles em regime de urgência foram objeto de emenda substitutiva aprovada e $51,7 \%$ dos deliberados pelas comissões foram alterados.

4. Pinto (2009) revisou os textos das constituições brasileiras e constatou movimentos cíclicos em que competências de elaboração legislativa dos poderes variavam de acordo com o período histórico, até alcançarem a conformação presente.

5. Estes são influenciados pelo status quo da política, por preferências pessoais, pela ideologia partidária e por demandas de atores externos, como grupos de interesse, eleitores em geral e a mídia.

6. Há 20 comissões permanentes na Câmara e 11 no Senado.

7. Tais políticas podem ser classificadas, de acordo com a tipologia desenvolvida por Lowi (1972) e Wilson (1973), como: distributiva (os custos são difusos e os benefícios, concentrados), redistributiva (ambos, custos e benefícios, são concentrados), regulatória (custos são concentrados e os benefícios, difusos) e majoritária (ambos, custos e benefícios, são difusos).

8. A saúde foi selecionada pela disponibilidade de método de classificação das proposições para essa política, variando desde temas estritos à área da saúde como aos que se relacionam com outras políticas, que reduzem riscos à saúde e abordam direitos, com potencial para observação de uma ampla variedade de conflitos.

9. A Câmara revisou 26 PLP e o Senado, 27.

10. No caso das MPV, além dos $77,7 \%$ convertidos em lei, os $10,2 \%$ ainda tramitando (situação permitida para aquelas apresentadas antes da Emenda Constitucional n. 32 de 2001) também têm força de lei, até que ocorra nova definição.

11. Ainda que fossem adicionadas as $52 \mathrm{MPV}$ que ainda tramitavam com força de lei, os PL teriam superado o número de MPV.

12. O Legislativo foi autor de $98,4 \%$ das propostas na via constitucional, $96,3 \%$ na complementar e 97,3\% na ordinária. 


\section{Fábio de Barros Correia Gomes}

13. Os deputados foram autores de $94,5 \%$ das propostas na via constitucional, $92,9 \%$ na complementar e $90,8 \%$ na ordinária, quando se consideram os projetos que ingressaram na Câmara entre 1999 e 2006.

14. Araújo (2009), que priorizou a perspectiva de tramitação no Senado de projetos apresentados entre 1989 e 2004, detectou proporções de conteúdos e ordenamentos semelhantes aos encontrados nesse estudo.

15. Das 19 PEC apresentadas pelo Executivo, 12 eram da área social.

16. Outros autores, como o Judiciário, também se destacaram na área administrativa (40,7\% das leis dessa área).

17. Já há registro de aprovação posterior ao período de estudo, de modo que tal comissão possui potencial para uma maior influência na produção legislativa.

18. Os senadores foram autores de 506 PEC e 11 foram convertidas em emendas constitucionais $(2,2 \%)$, enquanto os deputados obtiveram três êxitos (0,3\%) em 1.121 PEC e o Executivo, sete êxitos (36,8\%) em 19 PEC.

19. Um maior nível de relevância da agenda nessa via também foi sugerido pela inexpressividade quantitativa de propostas sobre homenagens (uma na Câmara e outra no Senado) e pela não aprovação destas.

20. Leis de autores que pertenciam à oposição na apresentação do PLP foram 7 ( 5 delas com comprometimento orçamentário) e 4 leis foram provenientes de parlamentares da coalizão na iniciação.

21. Cinco leis complementares na área econômica foram de autoria do Legislativo e 3, do Executivo.

22. Sete das 10 leis complementares na área administrativa foram de autoria do Executivo.

23. Os deputados foram autores de 208 leis ordinárias; os senadores, de 137; o Executivo, de 191; e 47 leis tiveram outros autores.

24. Na via constitucional, todas as 10 emendas com comprometimento do orçamento federal foram de autoria da coalizão (6 do Executivo e 4 de parlamentares).

25. Como também observaram Amorim e Santos (2003) nos PL de deputados apresentados em 1995. 


\section{REFERÊNCIAS BIBLIOGRÁFICAS}

ABRANCHES, Sérgio. (1988), "Presidencialismo de Coalizão: O Dilema Institucional Brasileiro". Dados, vol. 31, no 1, pp. 5-34.

ALEMÁN, Eduardo e CALVO, Ernesto. (2008), “Analyzing Legislative Success in Latin America: The Case of Argentina", in G. O'Donnell et alii (eds.), New Voices in the Study of Democracy in Latin America. Washington, D.C., Woodrow Wilson International Center for Scholars.

ALMEIDA, Acir S. e SANTOS, Fabiano. (2009), "Urgency Petitions and the Informational Problem in the Brazilian Chamber of Deputies". Journal of Politics in Latin America, vol. 3, pp. 81-110.

AMARAL, Ana Regina V. P. (2011), “O Parlamento Brasileiro: Processo, Produção e Organização Legislativa: O Papel das Comissões em Perspectiva Comparada", in J. Nicolau e R. Braga (orgs.), Para Além das Urnas: Reflexões sobre a Câmara dos Deputados. Brasília, Câmara dos Deputados, pp. 149-176.

AMES, Barry. (2001), The Deadlock of Democracy in Brazil. Ann Arbor, The University of Michigan Press.

AMORIM NETO, Octavio, COX, Gary e MCCUBBINS, Mathew. (2003), “Agenda Power in Brazil's Câmara dos Deputados, 1989-98”. World Politics, vol. 55, no 4, pp. 550-578.

AMORIM NETO, Octavio e SANTOS, Fabiano. (2003), “O Segredo Ineficiente Revisto: O que Propõem e o que Aprovam os Deputados Brasileiros". Dados, vol. 46, no 4, pp. 661-697.

ARAÚJO, Paulo M. (2009), O Bicameralismo no Brasil: As Bases Institucionais e Políticas do Desempenho Legislativo do Senado Federal (1989-2004). Tese de Doutorado. Belo Horizonte, Universidade Federal de Minas Gerais.

ARMIJO, Leslie E.; FAUCHER, Philippe e DEMBINSKA, Magdalena D. (2006), “Compared to What? Assessing Brazil's Political Institutions". Comparative Political Studies, no 39, pp. 759-786.

BRADY, David W. e VOLDEN, Craig. (2006), Revolving Gridlock. Politics and Policy from Jimmy Carter to George W. Bush (2a ed.). Boulder, Westview Press.

CARNEIRO, André Corrêa de S. (2009), Legislação Simbólica e Poder de Apreciação Conclusiva no Congresso Nacional. Dissertação de Mestrado, Rio de Janeiro, Instituto Universitário de Pesquisas do Rio de Janeiro / Centro de Formação da Câmara dos Deputados.

CARVALHO, Eduardo L. e GOMES, Fábio B. C. (2008), “Características da Tramitação de Projetos de Lei Ordinária Apresentados na Câmara dos Deputados entre 1999 e 2006", in D. Messenberg et alii (orgs.), Estudos Legislativos. Pensamento e Ação Política. Brasília, Câmara dos Deputados, pp. 285-289.

CINTRA, Antonio O. (2007), “O Congresso Nacional: É Preciso Mudanças? Exame de Algumas Propostas", in J. Nicolau e T. Power (orgs.), Instituições Representativas no Brasil: Balanço e Reforma. Belo Horizonte/Rio de Janeiro, UFMG Editora/IUPERJ, pp. 11-35. 


\section{Fábio de Barros Correia Gomes}

CRUZ, Márcia R. (2009), Legislativo Transformador? As Modificações do Legislativo nos Projetos de Lei do Executivo. Dissertação de Mestrado, Rio de Janeiro, Instituto Universitário de Pesquisas do Rio de Janeiro / Centro de Formação da Câmara dos Deputados. Disponível em http://www2.camara.gov.br/responsabilidade-social/edulegislativa/educacao-legislativa-1/posgraduacao/arquivos/publicacoes/teses-minter/DissertacaoMarciaRodriguesMinterIuperj.pdf. Acessado em 4/1/2011.

FIGUEIREDO, Argelina C. e LIMONGI, Fernando (1999), Congresso Nacional: Organização, Processo Legislativo e Produção Legal: Guia do Lobby I. Brasília, Inesc.

. (2004), "Modelos de Legislativo: O Legislativo Brasileiro em Perspectiva Comparada". Plenarium, ano I, no 41, pp. 41-56.

(2009), "Poder de Agenda e Políticas Substantivas", in M. Inácio e L. Rennó (orgs.), Legislativo Brasileiro em Perspectiva Comparada. Belo Horizonte, UFMG Editora, pp. $77-104$

GOMES, Fábio B. C. (2011), Interações entre o Legislativo e o Executivo Federal do Brasil na Definição de Políticas de Interesse Amplo: Uma Abordagem Sistêmica, com Aplicação na Saúde. Tese de Doutorado, Rio de Janeiro, Universidade do Estado do Rio de Janeiro. Disponível em http://bd.camara.gov.br/bd/bitstream/handle/bdcamara /6165/interacao_legislativo_gomes.pdf? sequence $=1$. Acessado em $25 / 7 / 2011$.

, CARVALHO, Eduardo L. e REIS, Rodolfo. (2009), “Projetos de Lei Ordinária Apresentados na Câmara dos Deputados entre 1999 e 2006: Tramitação Geral e dos Relacionados à Saúde". E-Legis - Revista Eletrônica do Programa de Pós-Graduação da Câmara dos Deputados, no 2. Disponível em http://inseer.ibict.br/e-legis/index. php/e-legis/article/view/10/8. Acessado em 4/1/2011.

JONES, Charles. (2005), The Presidency in a Separated System. Washington, D.C., Brookings Institution Press.

KINGSTONE, Peter R. e POWER, Timothy J. (2008), Democratic Brazil Revisited. Pittsburgh, University of Pittsburgh Press.

LANGONI, Carlos. (2010), Conta Corrente Analisa Crise Econômica da Grécia. Entrevista concedida ao programa Conta Corrente, Globo News, maio.

LELOUP, Lance T. e SHULL, Steven A. (2002), The President and Congress: Collaboration and Combat in National Policymaking. New York, Longman.

LOWI, Theodore J. (1972), "Four Systems of Policy, Politics, and Choice". Public Administration Review, vol. 32, no 4, pp. 298-310.

MCGUIRE, James W. (2010), Wealth, Health, and Democracy in East Asia and Latin America. New York, Cambridge University Press.

MELO, Marcus A. (2008), “Unexpected Successes, Unanticipated Failures: Social Policy from Cardoso to Lula”, in P. Kingstone e T. Power (eds.), Democratic Brazil Revisited. Pittsburgh, University of Pittsburgh Press, pp. 161-184.

MAINWARING, Scott. (1993), “Democracia Presidencialista Multipartidária: O Caso do Brasil”. Lua Nova, no 23/24, pp. 21-74. 
Cooperação, Liderança e Impasse entre o Legislativo e o Executivo na Produção...

PEREIRA, Carlos e MUELLER, Bernardo. (2000), “Uma Teoria da Preponderância do Poder Executivo: O Sistema de Comissões no Legislativo Brasileiro". Revista Brasileira de Ciências Sociais, vol. 15 no 43, pp. 43-67.

PINTO, Julio Roberto S. (2009), Poder Legislativo Brasileiro: Institutos e Processos. Rio de Janeiro, Forense.

SANTOS, Fabiano. (2003), Poder Legislativo no Presidencialismo de Coalizão. Belo Horizonte/Rio de Janeiro, UFMG Editora/Iuperj.

SANTOS, Maria Helena C. (1997), "Governabilidade, Governança e Democracia: Criação da Capacidade Governativa e Relações Executivo-Legislativo no Brasil PósConstituinte". Dados, vol. 40, no 3, pp. 335-376.

WILSON, James Q. (1973), Political Organizations. New York, Basic Books. 


\title{
ABSTRACT \\ Cooperation, Leadership, and Impasse between the Legislative and Executive Branches in Lawmaking by the Brazilian National Congress
}

This article discusses the relationship between Brazil's Legislative and Executive Branches in lawmaking. It identifies elements in the lawmaking system in Brazil and strategic interactions between hierarchical channels (Constitutional, complementary, and ordinary legislation) in the context of coalition Presidentialism. The model was applied to bills submitted between 1999 and 2006 and generated data that run counter to the widespread perception of a sharp divide between the respective agendas of the two branches and the hypothesis of absolute predominance by the Executive. However, the prevailing government coalition predominated in all the lawmaking channels. Various types of interaction between the branches were suggested, according to patterns of conflict and leadership by the players (leadership, cooperation, and impasse), as generated by the bills' contents.

Key words: Legislative; Executive; lawmaking; coalition; interactions

\author{
RÉSUMÉ \\ Coopération, Leadership et Impasse entre les Pouvoirs Législatif et \\ Exécutif dans la Production Législative du Congrès National au Brésil
}

Cet article aborde les rapports entre les pouvoirs Législatif et Exécutif lors de la production de normes légales. Il identifie des éléments du système brésilien de production législative et des interactions stratégiques en fonction de voies hiérarchisées (constitutionnelle, complémentaire et ordinaire) dans le contexte du présidentialisme de coalition. Ce modèle a été appliqué aux propositions présentées entre 1999 et 2006 et a produit des données qui s'opposent à la perception selon laquelle il y aurait une démarcation d'agenda entre ces Pouvoirs. Elles contredisent également la thèse selon laquelle il y aurait une prédominance absolue de l'Exécutif. Toutefois, la coalition a prédominé dans toutes les voies. l'existence de plusieurs types d'interaction entre les Pouvoirs est ici suggérée en fonction des modèles de conflit et de leadership des acteurs (leadership, coopération et impasse) tels qu'ils sont engendrés par le contenu des propositions.

Mots-clés: Législatif; Exécutif; production législative; coalition; interactions 